\section{Ankara Üniversitesi Eğitim Bilimleri \\ Fakültesi Özel Eğitim Dergisi}

2021, 22(4), 969-998
DERLEME

Gönderim Tarihi: 03.03.20

Kabul Tarihi: 22.11 .20

Erken Görünüm: 27.11.20

\title{
Otizm Spektrum Bozukluğu Olan Bireylere Sosyal Etkileşim ve İletişim Becerilerinin Öğretiminde İpucunun Giderek Arttırılması: Sistematik Bir Derleme*
}

\author{
Burcu Ülke-Kürkçüoğlu (D)
}

\author{
Dinçer Saral (D)2
}

\begin{abstract}
$\ddot{O} z$
Giriş: Bu çalışmanın amacı, yanlışsız öğretim yöntemlerinden olan ipucunun giderek arttırılmasıyla öğretim (IGA) sunularak otizm spektrum bozukluğu (OSB) olan bireylere sosyal etkileşim ve iletişim becerilerinin öğretildiği araştırmaları demografik özellikler, yöntemsel parametreler ve bulgular açısından betimsel olarak analiz etmektir.

Yöntem: Çalışma kapsamında, dört farklı veritabanının (EBSCOhost, ScienceDirect, Jstor ve SAGE) gelişmiş arama motoruna, ilgili anahtar kelimeler yazılarak elektronik taramalar yapılmıştır. Tarama sonucunda 390 çalışmaya ulaşılmıştır. Bu çalışmalar dahil etme ölçütleri olarak (a) OSB olan bireylerle yürütülmesi, (b) ipucunun giderek arttırılmasıyla öğretim yönteminin kullanılması, (c) tek denekli araştırma modellerinden biriyle desenlenmesi, (d) bir sosyal etkileşim ve iletişim becerisinin öğretilmesi, (e) Ocak 2003-Mayıs 2020 yılları arasında yürütülmesi ve (f) Türkçe ve/veya İngilizce dilinde hakemli bir dergide yayımlanması açısından incelenmiştir ve toplamda 35 araştırma, kapsama alınarak analiz edilmiştir.
\end{abstract}

Bulgular: Araştırma sonucunda, farklı yaş grubundaki OSB olan bireylere İGA sunularak sosyal etkileşim ve iletişim becerilerinin öğretilebildiği görülmüştür.

Tartışma: Araştırmanın bulguları tartışılarak ileri çalışmalara yönelik önerilerde bulunulmuştur.

Anahtar sözcükler: Otizm, sosyal etkileşim, iletişim, yanlışsız öğretim, ipucunun giderek arttırılması.

Atıf için: Ülke-Kürkçüoğlu, B., \& Saral, D. (2021). Otizm spektrum bozukluğu olan bireylere sosyal etkileşim ve iletişim becerilerinin öğretiminde ipucunun giderek arttırılması. Ankara Üniversitesi Eğitim Bilimleri Fakültesi Özel Eğitim Dergisi, 22(4), 969-998. https://doi.org/10.21565/ozelegitimdergisi.697976

\footnotetext{
*Bu çalışma 3. Ulusal Disiplinlerarası Erken Çocuklukta Müdahale Kongresi’nde (UDEMKO 2016) poster bildiri olarak sunulmuştur.

${ }^{1}$ Sorumlu Yazar: Doç. Dr., Anadolu Üniversitesi, E-posta: bulkekurkcuoglu@ anadolu.edu.tr, https://orcid.org/0000-00030187-9742

${ }^{2}$ Arş. Gör., Hacettepe Üniversitesi, E-posta: dincersaral@hacettepe.edu.tr, https://orcid.org/0000-0003-0795-255X
} 


\section{Giriș}

Dünyada ve ülkemizde günden güne sayısı artan otizm spektrum bozukluğu (OSB) tanısı alan bireylerin en temel sorunlarından biri, sosyal etkileşim ve sosyal iletişim alanlarında gösterdikleri yetersizliklerdir (American Psychiatric Association [APA], 2013; Maenner vd., 2020). OSB tanısı için kullanılan Ruhsal Bozuklukların Tanısal ve Sayımsal El Kitabı'na (The Diagnostic and Statistical Manual of Mental Disorders, Fifth Edition, [DSM-5]) göre OSB; (a) sınırlı ve yinelenen ilgi ve davranış örüntüleri ve (b) sosyal iletişim ve sosyal etkileşimde yetersizliklerle kendini göstermektedir (APA, 2013). DSM-5'te belirtilen sosyal iletişim ve sosyal etkileşim tanı ölçütleri kategorilerinde sınırlı duygu paylaşımı, arkadaş edinimi, göz kontağı kurma gibi sorunlara vurgu yapılarak OSB olan bireylerin sosyal etkileşime girme, anlama ve sürdürmede yetersizliklere sahip oldukları ifade edilmektedir. Ayrıca, bu bireylerin sosyal uyaranları anlamada, mimik ve yüz ifadelerini anlamlandırma ve kullanma gibi birçok beceride yetersizlik yaşamalarından dolayı problem davranış sergiledikleri ifade edilmektedir (Vuran \& Usluer, 2012). OSB olan bireylerin başkalarıyla etkili biçimde iletişim kurması, bağımsızlık kazanması ve karşılaştı̆̆ 1 sorunlarla başa çıkması için sosyal etkileşim becerilerini öncelikli olarak öğrenmesi gerekmektedir (Matson vd., 2007).

Günümüzde, OSB olan bireylere sosyal etkileşim ve iletişim becerilerinin öğretiminde birçok uygulamadan yararlanılırken, bu bireylere çeşitli becerilerin öğretiminde model olma, doğal öğretim, yanlışsız öğretim gibi bilimsel dayanaklı uygulamaların önemi vurgulanmaktadır (Steinbrenner vd., 2020). Yanlışsız öğretim yöntemleri arasında yer alan uygulamalardan biri de ipucunun giderek artırılmasıyla öğretimdir (İGA). İGA sürecine bireye en 1lımlı ipucunun sunulmasıyla başlanmakta, gerektikçe ipucunun türü ve yoğunluğunda değişiklikler yapılmakta ve en az 1lımlı ipucuna doğru sistematik şekilde geçiş yapılmaktadır. Ancak, ipucu düzeyleri arasında yapılan bu geçişler bireyin belirlenen yanıt aralığı süresince tepkide bulunmamasıyla gerçekleştirilmektedir. Bu öğretim yöntemi için en az üç düzeyli bir ipucu dizisi gerekmektedir (Barton \& Pavilanis, 2012; Seaver \& Bourret, 2014; Tekin-İftar \& Kırcaali-İftar, 2013). Bir öğretim oturumunda hedef uyaran sunularak bireyin bağımsız şekilde tepkide bulunması için yanıt aralığı süresince beklenir. Birey yanlış tepki verir ya da tepkide bulunmazsa, bireye ipucu dizisinde yer alan ilk ipucu düzeyi sunulur ve bireyin tepkisi beklenir. Bireyin yanıt aralığı süresince yine yanlış tepkide bulunması ya da tepkide bulunmaması halinde, daha az ılımlı olan bir sonraki ipucu düzeyine geçilir ve bireyin tepkisi beklenir. Bu süreç, bireyin hedef davranışı doğru biçimde sergileyinceye ya da tüm ipuçları sunuluncaya kadar devam eder. Birey herhangi bir ipucu düzeyinde hedef davranışı doğru biçimde sergilerse pekiştirilir (Tekin-İftar \& Kırcaali-İftar, 2013). Diğer yanlışsız öğretim yöntemlerine göre İGA öğretiminde, bireyin hata yapma olasılığının daha yüksek olduğu ya da öğretimin daha çok zaman aldığı belirtilmektedir (Libby vd., 2008; Yanardağ vd., 2011). Ancak İGA öğretimi, bireye herhangi bir ipucuna bağımlılık geliştirmeden bağımsız tepkide bulunma ve gerektiğinde en az 1lımlı ipucunu seçme firsatı tanımaktadır (Barton \& Pavilanis, 2012). Ayrıca bu öğretim yöntemi, doğal etkileşimi destekleyerek uygulamacının yeni beceriler kazandırmasına ve sistematik olarak ipuçlarını silikleştirmesine izin vermektedir (Barton \& Pavilanis, 2012). Son yıllarda konuya ilişkin araştırmalarda, İGA öğretiminin (a) günlük rutinler, ortamlar ve etkinlikler içerisine kolayca gömülmesi, (b) etkili bir yetişkin-çocuk etkileşimini desteklemesi, (c) bireyi daha fazla bağımsızlaştırarak motive etmesi ve (d) bireyin ipucuna bağımlılık geliştirme olasılığını en aza indirmesi gibi nedenlerle daha çok tercih edildiği görülmektedir (Barton \& Pavilanis, 2012; Barton \& Wolery, 2008; Filla vd., 1999; Ülke-Kürkçüoğlu, 2015; West \& Billingsley, 2005).

İGA öğretiminin, farklı yaş ve yetersizlik grubundaki bireylere tek basamaklı ya da zincirleme beceri veya davranış kazandırmada etkili olduğunu gösteren çok sayıda araştırma bulunmaktadır (Ahlgrim-Delzell vd., 2014; Ault \& Griffen, 2013; Barton \& Wolery, 2010; Browder vd., 2012; DiCarlo \& Reid, 2004; Libby vd., 2008; Taylor \& Hoch, 2008). Son yıllarda OSB olan bireylerle yürütülen araştırmalar incelendiğinde, İGA öğretiminin özellikle iletişim becerileri (Xin \& Leonard, 2015), günlük yaşam becerileri (Bouck vd., 2014), oyun becerileri (Barton, 2015; Ülke-Kürkçüoğlu, 2015) ve mesleki beceriler (Aljehany \& Bennet, 2019; Cannella-Malone vd., 2017) gibi becerilerin öğretiminde kullanıldığı görülmektedir. Alanyazında yalnızca İGA öğretiminin değerlendirildiği ya da İGA öğretimini de kapsayan çalışmaların incelendiği, üç farklı derleme çalışmasına rastlanmaktadır (Ault vd., 1989; Doyle vd., 1988; Shepley vd., 2019). Doyle ve diğerlerinin (1988) çalışmasında İGA öğretiminin sunulduğu araştırmaların incelendiği; ancak, Ault ve diğerlerinin (1989) çalışmasında orta ve ileri derecede yetersizliği olan öğrencilerin öğretimi için yürütülen karşılaştırma çalışmalarının içinde İGA öğretimine ilişkin değerlendirmelere yer verildiği görülmektedir. Yalnızca İGA araştırmalarına odaklanan Shepley ve diğerleri (2019) tarafından yürütülen ve en güncel derlemede ise 1988-2016 yılları arasında ERIC, Psychoinfo ve Medline veri tabanlarında, ilgili anahtar kelimeler kullanılarak 123 hakemli dergide yayımlanan çalışma inceleme kapsamına alınmıştır. Bu çalışmaların her biri katılımcı özellikleri, uygulama ortamı ve koşulları, 
İGA’nın kullanım biçimi, etkililik, verimlilik ve bilimsel dayanak açısından incelenmiştir. Çalışma sonucunda İGA'nın 13 yaşında ya da daha ileri yaşta orta derecede zihinsel yetersizliği olan bireylere toplumsal, öz bakım ve mesleki becerilerle ilişkili zincirleme becerilerin öğretiminde bilimsel dayanaklı bir uygulama olduğu rapor edilmiştir. Sözü edilen derleme çalışmalarının daha geniş bir bakış açısıyla çalışmaları ele aldığı ve özellikle zihinsel yetersizliği olan bireylerin kullanımına ilişkin güncel bir sonuç ortaya koyduğu görülmektedir. Ancak alanyazında İGA öğretiminin sunulduğu araştırmaları, OSB açısından inceleyen ve sonuçları rapor eden bir derleme çalışmasına rastlanmamaktadır. Ülkemizde ise OSB olan bireylerin eğitiminde İGA'nın daha fazla tercih edilmeye başlandığı; ancak, lisansüstü tezler dahil halen yürütülen araştırmaların sınırlı sayıda olduğu dikkat çekmektedir (Bilmez, 2014; Ergin, 2017; Gıc1-Vatansever, 2018; Kurnaz, 2018; Saral \& Ülke-Kürkçüoğlu, 2020; Topuz \& Ülke-Kürkçüoğlu, 2019; Ülke-Kürkçüoğlu, 2015; Yanardağ vd., 2011). Ayrıca, İGA öğretimi sunularak OSB olan bireylere sosyal etkileşim ve iletişim becerilerinin öğretildiği araştırmaların derlenerek betimsel analizinin yapıldığ eğitiminde, araştırmacıların ve uygulamacıların bu yöntemi kullanmalarını teşvik etmek amacıyla böyle bir gereksinim ortaya çıkmaktadır. Dolayısıyla bu gerekçeler ışı̆̆ında çalışmada izleyen sorulara yanıt aranmaktadır: (a) Araştırmalardaki katılımcıların demografik özellikleri (yaş, cinsiyet) nelerdir? (b) Araştırmalarda uygulama süreci hangi uygulamacılarla (araştırmacı, öğretmen, vb.) yürütülmektedir? (c) Araştırmalarda hangi ortamlar (ev, okul, vb.) kullanılmaktadır? (d) Araştırmalarda hangi tek denekli araştırma modelleri tercih edilmektedir? (e) Araştırmalarda öğretilen sosyal etkileşim ve iletişim becerileri nelerdir? (f) Araştırmalarda İGA öğretiminin kullanım türüne (tek başına, başka bir uygulamayla, vb.) göre dağılımı nedir? (g) Araştırmalardaki İGA sunumuyla kullanılan ipucu hiyerarşisi ve türleri nelerdir? (h) Araştırmaların izleme, genelleme ve sosyal geçerlik verileri ne düzeydedir? (1) Araştırmaların genelleme çalışmalarında kullandıkları genelleme türleri nelerdir? (i) Araştırmaların uygulama ve gözlemciler arası güvenirlik verileri mevcut mudur? (j) Araştırmaların edinim, izleme, genelleme ve sosyal geçerlik bulguları nelerdir?

\section{Yöntem}

\section{Alanyazın Tarama Süreci}

Çalışma kapsamında, Ocak 2003 ile Mayıs 2020 arasında OSB olan bireylere sosyal etkileşim ve iletişim becerilerinin öğretiminde, İGA öğretiminin sunulduğu araştırmalar betimsel olarak incelenmiştir. Bu çalışmada, incelenen her yıl içinde İGA öğretimi sunularak sosyal etkileşim ve iletişim becerilerinin öğretildiği en az bir araştırmanın olması dikkate alınmıştır. Ancak 2001 - 2002 yılları arasında herhangi bir çalışmaya rastlanılmamıştır. Dolayısıyla 2003 yılından itibaren yayımlanan araştırmaların incelenmesi planlanmıştır. Bu doğrultuda, elektronik ortamda gelişmiş arama için "autism", "system of least", "least to most", "social communication", "social interaction" anahtar sözcükleri kullanılarak EBSCOhost, ScienceDirect, Jstor ve SAGE veritabanları taranmıştır. İlk tarama sonucunda, EBSCOhost, ScienceDirect, Jstor ve SAGE veritabanlarında sırasıyla 151, 110, 39 ve 90 olmak üzere toplam 390 çalışmaya ulaşılmıştır. Şekil 1'de veri tabanlarında ulaşılan araştırma sayıları ile birlikte, dahil etme/hariç tutma ölçütleri çerçevesinde izlenen tarama sürecini betimlemek için alanyazın tarama akışı sunulmuştur.

\section{Dâhil Etme ve Hariç Tutma Ölçütleri}

Araştırmaların çalışmaya dahil edilmesi için izleyen ölçütler dikkate alınmıştır: (a) OSB olan bireylerle yürütülmesi, (b) ipucunun giderek arttırılmasıyla öğretim yönteminin araştırmanın tümünde ya da bir kısmında kullanılması, (c) tek denekli araştırma modellerinden biriyle desenlenmesi, (d) bir sosyal etkileşim ve iletişim becerisinin öğretilmesi, (e) Ocak 2003-Mayıs 2020 yılları arasında yürütülmesi ve (f) Türkçe ve/veya İngilizce dilinde hakemli bir dergide yayımlanması. Araştırma kapsamından hariç tutma için izleyen ölçütler belirlenmiştir: (a) katılımcıların tamamının OSB tanılı olmaması, (b) tek denekli araştırma modelleri dışındaki bir yöntemle araştırmaların tasarlanması ve (c) 2003 yılı öncesinde yürütülen araştırma olması. Dahil etme ölçütlerinde yer alan ipucunun giderek arttırılmasıyla öğretimin kullanımına ilişkin araştırmaların tümü ifadesi, araştırmanın başından sonuna ana bağımsız değişken olarak İGA'nın tek başına ya da bir başka uygulamayla birlikte sunulduğunu belirtmek için kullanılmıştır. Araştırmaların bir kısmı ifadesi ise araştırmalardaki uygulama süresinin bir kısmında İGA'nın sunulduğunu belirtmek için kullanılmıştır. Dahil etme ve hariç tutma ölçütleri dikkate alındığında 35 araştırma çalışma kapsamına alınmıştır. Alanyazın incelemesi doğrultusunda OSB olan bireylere yönelik sosyal etkileşim ve iletişim becerisi öğretimine ilişkin yürütülen araştırmalar (a) katılımcıların demografik özellikleri (yaş, cinsiyet), (b) uygulamacı özellikleri, (c) araştırma ortamı, (d) araştırma modeli, (e) bağımlı değişkenler (öğretilen sosyal etkileşim ve iletişim becerileri), (f) bağımsız değişken olarak İGA öğretiminin kullanım türü (tek 


\section{Şekil 1.}

Alanyazın Taramasına İlișkin Aklş

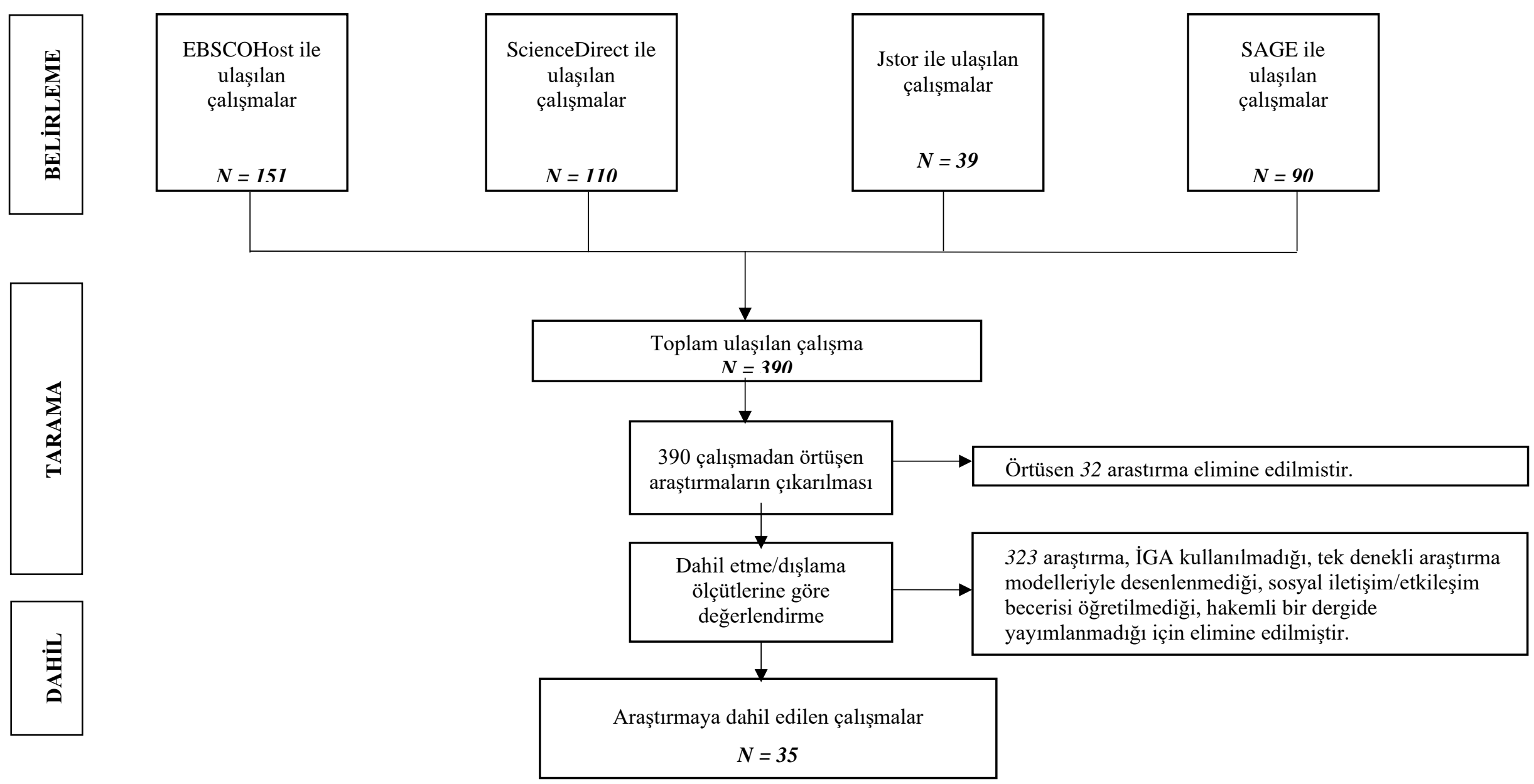


başına, başka bir uygulamayla, vb.), (g) İGA sunumuyla kullanılan ipucu hiyerarşisi ve türleri, (h) araştırmaların izleme, genelleme ve sosyal geçerlik verileri, (1) araştırmaların genelleme çalışmalarında kullandıkları genelleme türleri, (i) uygulama ve gözlemciler arası güvenirlik verileri, (j) araştırmaların edinim, izleme, genelleme ve sosyal geçerlik bulguları olmak üzere farklı kategorilerde ele alınarak betimsel olarak analiz edilmiştir.

\section{Kodlayıcılar Arası Güvenirlik Süreci}

Araştırmada betimsel analiz sürecine ilişkin kodlayıcılar arası güvenirlik, araştırma kapsamındaki çalışmaların \%50'sinin yansız atama yoluyla seçilmesiyle gerçekleştirilmiştir. Bu amaçla, Özel Eğitim bölümünde doktora yapan ikinci yazar ve bağımsız bir kodlayıcı betimsel analize dahil edilen araştırmaları Tablo 1'de belirtilen değişkenlere göre ayrıntılı bir biçimde değerlendirmiştir. Ardından, araştırmacılar bir araya gelerek listelerini karşılaştırmıştır. Kodlayıcılar, değişkenlere ilişkin tutarlılığı belirlemek amacıyla "[görüş birliği / (görüş birliği + görüş ayrılığı) X 100]” formülünü kullanmış ve kodlayıcılar arası güvenirlik yüzdesi hesaplanmıştır. Çalışmanın kodlayıcılar arası güvenirliği \%100 olarak hesaplanmıştır.

\section{Bulgular}

Çalışmaya dâhil edilen araştırmalar, izleyen başlıklar altında 11 farklı kategoriye göre incelenmiştir. Araştırmadan elde edilen veriler Tablo 1'de ayrıntılı olarak sunulmuştur.

\section{Katılımcıların Demografik Özellikleri}

Araştırma kapsamına alınan araştırmaların tümünde katılımcı olarak toplam 117 OSB olan birey yer almıştır. Araştırmalarda 51 katılımcı 2-5 yaş (ör. Charlop \& Greenberg, 2009; Hansen vd., 2019), 31 katılımcı 69 yaş (ör. Thiemann \& Goldstein, 2004), 22 katılımcı 10-13 yaş (ör. Xin \& Leonard, 2015), 2 katılımc1 14-17 yaş (Cannella-Malone vd., 2010; Lund \& Troha, 2008) ve 7 katılımcı 18-21 yaş aralığında (ör. Walsh vd., 2018) olduğu görülmüştür. Bu araştırmaların bir kısmında $(n=17)$ tüm katılımcıların yukarıda belirtilen yaş aralıklarının içinde yer aldığı görülmüştür (ör. Barton vd., 2018). Ancak araştırmaların bir kısmında $(n=16)$ katılımcılardan birinin belli bir yaş aralığında olduğu; aynı çalışmada diğer katılımcıların ise farklı bir yaş aralığında olduğu görülmüştür. Örneğin, Raulston ve diğerleri (2019) tarafından çalışmaya katılan üç çocuktan ikisinin 6, bir diğerinin 3,5 yaşında olduğu rapor edilmiştir. Araştırmaların beşinde (ör. Wilson vd., 2017) en az katılımcı sayısı olarak tek katılımcıyla çalışıldığı; araştırmaların yalnızca ikisinde (Shillingsburg \& Cariveau, 2016; Walsh vd., 2018) en fazla katılımcı sayısı olarak 7 katılımcıyla çalışıldığı dikkat çekmektedir. Bir araştırmada iki farklı araştırma yürütüldüğü; ancak, her iki çalışmada da aynı katılımcının yer aldığı belirtilmiştir (Barton vd., 2019). Bir araştırmada ise on katılımcıdan sekizine ilişkin her bir katılımcının yaş bilgisi verilmemesine rağmen bu katılımcıların 5-9 yaş aralığında olduğu rapor edilmiştir (Shillingsburg \& Cariveau, 2016).

Katılımcıların 85'i erkeklerden, 32'si kızlardan oluşmuştur. Araştırmaların 13'ünde (ör. Huskens vd., 2013) yalnızca erkek, 4'ünde (ör. Cannella-Malone vd., 2010) yalnızca kız ve kalan araştırmalarda (ör. Tetreault \& Lerman, 2010) ise hem kız hem erkek katılımcılarla çalışılmıştır.

\section{Uygulamacı Özellikleri}

Araştırma kapsamına dahil edilen araştırmalarda yer alan uygulamacılar dikkate alındığında, araştırmaların 23'ünde (ör. Schaefer vd., 2019) araştırmacıların kendilerinin, dördünde (ör. Kern vd., 2007) öğretmenlerin uygulamacı olduğu görülmüştür. Araştırmaların birinde uygulamacı olarak yüksek lisans öğrencisi ve ergoterapist yardımcısı yer alırken (Lund \& Troha, 2008); birinde de yardımcı öğretmen uygulamacı olmuştur (Xin \& Leonard, 2015). Araştırmalardan birinde ise uygulamacı olarak yalnızca akran yer alırken (ThiemannBourque vd., 2016), bir diğer araştırmada hem akran hem de araştırmacı uygulamayı yürütmüştür (Hansen vd., 2019). Geriye kalan araştırmalar içinde üç araştırmada yalnızca ebeveyn tarafından uygulama gerçekleştirilmişken (Erturk vd., 2020; Hansen vd., 2018; Raulston vd., 2019), başka bir araştırmada da anne ve araştırmacı uygulamacı rolünü üstlenmiştir (Van Der Meer vd., 2013).

\section{Araștırma Ortamı}

Araştırmaların yürütüldüğü ortamlara göre dağılımları incelendiğinde, araştırmaların yalnızca ikisinin genel bir ifadeyle okul ortamında (Queiroz vd., 2020; Xin \& Leonard, 2015), 14'ünün özel olarak sinıf ortamında (ör. Lund \& Troha, 2008) yürütüldüğü rapor edilmiştir. Araştırmaların 12'sinde (ör. Tetreault \& Lerman, 2010) uygulamanın klinik ortamda yürütüldüğü belirtilmiştir. 
OTIZM SPEKTRUM BOZUKLUĞU OLAN BIREYLERE SOSYAL ETKILESSIM VE ILLETISIMM BECERILERININ

Tablo 1

Araştırma Kapsamında İncelenen Araştırmalar

\begin{tabular}{|c|c|c|c|c|c|c|c|c|c|c|c|c|c|c|}
\hline \multirow[b]{2}{*}{ Kaynak } & \multirow{2}{*}{$\begin{array}{l}\text { Cinsiyet } \\
\text { (Yaş, Ay) }\end{array}$} & \multirow[b]{2}{*}{ Ortam } & \multirow[b]{2}{*}{ Uygulamac1 } & \multirow[b]{2}{*}{ Hedef beceriler } & \multirow[b]{2}{*}{$\begin{array}{l}\text { İGA kullanım } \\
\text { türü }\end{array}$} & \multirow[b]{2}{*}{ İpucu türleri } & \multirow{2}{*}{$\begin{array}{l}\text { Araştırma } \\
\text { modeli }\end{array}$} & \multirow[b]{2}{*}{ İzl } & \multicolumn{3}{|c|}{ Gnl } & \multirow[b]{2}{*}{ SG } & \multirow{2}{*}{$\begin{array}{l}\text { GAG } \\
\text { ve } \\
\text { UG }\end{array}$} & \multirow[b]{2}{*}{ Bulgular } \\
\hline & & & & & & & & & KA & OA & $\mathrm{AA}$ & & & \\
\hline $\begin{array}{l}\text { Thiemann } \\
\& \\
\text { Goldstein, } \\
2004\end{array}$ & $\begin{array}{c}\text { E-7 } \\
\text { E-9,1 } \\
\text { E-7,6 } \\
\text { E-7,7 } \\
\text { E-6,8 }\end{array}$ & Sinif & Araştırmacı & $\begin{array}{l}\text {-Dikkat yöneltme, } \\
\text {-Yorum yapma, } \\
\text {-Övme, } \\
\text {-İstek bildirme, } \\
\text {-Yanıt verme }\end{array}$ & $\begin{array}{c}\text { Bir kısmında } \\
\text {-Tek başına, } \\
\text {-Hata } \\
\text { düzeltmesi } \\
\text { amaçlı }\end{array}$ & $\begin{array}{c}\text { Jest } \\
\text { Sözel }\end{array}$ & ÇBM & + & - & - & - & $\begin{array}{c}+ \\
\text { (Öğretmen, } \\
\text { Lisansüstü } \\
\text { öğrencileri) }\end{array}$ & ++ & $\begin{array}{c}\text { Ed. } 5 / 5 \\
\text { İzl. 4/5 } \\
\text { SG. 18/21 }\end{array}$ \\
\hline $\begin{array}{l}\text { Kern vd., } \\
2007\end{array}$ & $\begin{array}{l}\text { E-3,5 } \\
\text { E-3,2 }\end{array}$ & Sinif & Öğretmen & $\begin{array}{l}\text {-Selamlama, } \\
\text {-El sallama }\end{array}$ & $\begin{array}{c}\text { Tümünde } \\
\text { - Şark1+İGA }\end{array}$ & $\begin{array}{c}\text { İB, } \\
\text { Sözel, } \\
\text { Fiziksel }\end{array}$ & $\mathrm{ABAB}$ & - & - & - & - & $\begin{array}{c}+ \\
\text { (Anne ve } \\
\text { babalar, } \\
\text { bakıc1, } \\
\text { öğretmen) }\end{array}$ & +- & $\begin{array}{c}\text { Ed. } 2 / 2 \\
\text { SG. Sayı } \\
\text { belirtilmemiş }\end{array}$ \\
\hline $\begin{array}{c}\text { Lund \& } \\
\text { Troha } \\
2008\end{array}$ & $\begin{array}{l}\text { E-17 } \\
\text { E-13 } \\
\text { K-12 }\end{array}$ & Sinif & $\begin{array}{c}\text { YL öğrenci, } \\
\text { Ergoterapist } \\
\text { Asistanı }\end{array}$ & -Talep etme & $\begin{array}{l}\text { Bir kısmında } \\
\text {-PECS'in } 1 . \\
\text { evresinde } \\
\text {-Tek başına }\end{array}$ & $\begin{array}{l}\text { İB, } \\
\text { Sözel, } \\
\text { KF, TF }\end{array}$ & ÇBM & - & - & - & - & - & +- & Ed. $1 / 3$ \\
\hline $\begin{array}{l}\text { Charlop \& } \\
\text { Greenberg, } \\
2009\end{array}$ & $\begin{array}{l}\text { E-4,6 } \\
\text { E-4,5 } \\
\text { E-4,7 }\end{array}$ & Sinif & Araştırmacı & -İletişim başlatma & $\begin{array}{l}\text { Bir kısmında } \\
\text {-Tek başına } \\
\text {-Replik } \\
\text { öğretimi } \\
\text { amaçlı }\end{array}$ & - & $\begin{array}{l}\text { Değişen } \\
\text { Ölçütler } \\
\text { Modeli }\end{array}$ & - & - & - & + & - & ++ & $\begin{array}{c}\text { Ed. } 3 / 3 \\
\text { Gnl. } 3 / 3\end{array}$ \\
\hline $\begin{array}{l}\text { Cannella- } \\
\text { Malone } \\
\text { vd., } 2010\end{array}$ & $\begin{array}{c}\text { K-6 } \\
\text { K-14 }\end{array}$ & $\begin{array}{c}\operatorname{Sin} 1 f(1) \\
\operatorname{Ev}(1)\end{array}$ & Araştırmacı & $\begin{array}{l}\text {-Selamlama, } \\
\text {-Talep etme, } \\
\text {-Yanit verme }\end{array}$ & $\begin{array}{c}\text { Tümünde } \\
\text {-PECS+İGA }\end{array}$ & $\begin{array}{l}\text { İB, } \\
\text { Sözel, } \\
\text { Jest, } \\
\text { Fiziksel }\end{array}$ & ÇBM & + & - & - & - & $\begin{array}{c}+ \\
\text { (Ebeveyn, } \\
\text { Öğretmen) }\end{array}$ & ++ & $\begin{array}{l}\text { Ed. } 2 / 2 \\
\text { İzl. } 1 / 1 \\
\text { SG. } 4 / 4\end{array}$ \\
\hline $\begin{array}{l}\text { Tetreault \& } \\
\text { Lerman, } \\
2010\end{array}$ & $\begin{array}{l}\text { E-5,5 } \\
\text { E-8,2 } \\
\text { K-4,4 }\end{array}$ & Klinik & Araştırmacı & $\begin{array}{c}\text {-Göz kontağ } 1, \\
\text {-Oyuncak } \\
\text { paylaşma, } \\
\text {-Sohbeti } \\
\text { başlatma/sürdürme }\end{array}$ & $\begin{array}{l}\text { Bir kısmında } \\
\text {-Tek başına } \\
\text {-Uyarlama } \\
\text { amaçlı }\end{array}$ & $\begin{array}{c}\text { İB, } \\
\text { Jest, } \\
\text { Jest+K1smi } \\
\text { sözel } \\
\text { Jest+Tam } \\
\text { sözel }\end{array}$ & ÇBM & + & - & - & + & - & ++ & $\begin{array}{l}\text { Ed. 2/3 } \\
\text { İzl. 1/1 } \\
\text { Gnl. 1/1 }\end{array}$ \\
\hline
\end{tabular}


OTIZM SPEKTRUM BOZUKLUĞU OLAN BIREYLERE SOSYAL ETKILESSIM VE İLETISSIM BECERILERINININ

Tablo 1 (devamı)

\begin{tabular}{|c|c|c|c|c|c|c|c|c|c|c|c|c|c|c|}
\hline \multirow[b]{2}{*}{ Kaynak } & \multirow{2}{*}{$\begin{array}{c}\text { Cinsiyet } \\
\text { (Yaş, Ay) }\end{array}$} & \multirow[b]{2}{*}{ Ortam } & \multirow[b]{2}{*}{ Uygulamac1 } & \multirow[b]{2}{*}{ Hedef beceriler } & \multirow{2}{*}{$\begin{array}{l}\text { İGA kullanım } \\
\text { türü }\end{array}$} & \multirow[b]{2}{*}{ İpucu türleri } & \multirow{2}{*}{$\begin{array}{l}\text { Araştırma } \\
\text { modeli }\end{array}$} & \multirow[b]{2}{*}{ İzl } & \multicolumn{3}{|c|}{ Gnl } & \multirow{2}{*}{\multicolumn{2}{|c|}{$\begin{array}{l}\text { GAG } \\
\text { ve } \\
\text { UG }\end{array}$}} & \multirow[b]{2}{*}{ Bulgular } \\
\hline & & & & & & & & & KA & $\mathrm{OA}$ & $\mathrm{AA}$ & & & \\
\hline $\begin{array}{l}\text { Huskens vd., } \\
2013\end{array}$ & $\begin{array}{c}\text { E-10,10 } \\
\text { E-11,5 } \\
\text { E-11,10 } \\
\text { E-12,3 } \\
\text { E-8,9 }\end{array}$ & Klinik & Araştırmacı & -Soru sorma & $\begin{array}{l}\text { Tümünde } \\
\text {-Tek başına }\end{array}$ & $\begin{array}{l}\text { İB, } \\
\text { Jest, } \\
\text { Sözel }\end{array}$ & ÇBM & + & - & - & - & - & ++ & $\begin{array}{l}\text { Ed. } 5 / 5 \\
\text { İzl. } 5 / 5\end{array}$ \\
\hline $\begin{array}{l}\text { Van Der } \\
\text { Meer vd., } \\
2013\end{array}$ & $\begin{array}{l}\text { E-10 } \\
\text { K-11 }\end{array}$ & $\begin{array}{c}\operatorname{Ev}(1) \\
\text { Sinif (1) }\end{array}$ & $\begin{array}{c}\text { Anne } \\
\text { Araştırmacı }\end{array}$ & $\begin{array}{l}\text {-Talep etme, } \\
\text {-selamlama, } \\
\text {-Yanit verme, } \\
\text {-Nezaket bildirme }\end{array}$ & $\begin{array}{c}\text { Bir kısmında } \\
\text {-Tek başına } \\
\text {-Cihaz } \\
\text { Kullanımı+İGA }\end{array}$ & $\begin{array}{c}\text { Sözel, } \\
\text { Model, } \\
\text { Fiziksel }\end{array}$ & DUM & + & - & - & + & $\begin{array}{c}+ \\
\text { (Kat1lımc1) }\end{array}$ & ++ & $\begin{array}{c}\text { Ed.2/2 } \\
\text { İzl.2/2 } \\
\text { Gnl. 1/1 } \\
\text { SG. 1/1 }\end{array}$ \\
\hline $\begin{array}{l}\text { Waddington } \\
\text { vd., } 2014\end{array}$ & $\begin{array}{c}\text { E-7 } \\
\text { E-8 } \\
\text { E-10 }\end{array}$ & Klinik & Araştırmacı & $\begin{array}{c}\text {-Talep etme } \\
\text {-Teşekkür etme }\end{array}$ & $\begin{array}{c}\text { Bir kısmında } \\
\text {-Tek başına } \\
\text {-Cihaz } \\
\text { Kullanımı+İGA }\end{array}$ & $\begin{array}{c}\text { Jest }+ \text { Sözel, } \\
\text { KF, } \\
\text { TF }\end{array}$ & ÇBM & + & + & - & - & - & ++ & $\begin{array}{c}\text { Ed. 3/3 } \\
\text { İzl. 2/2 } \\
\text { Gnl. 2/2 }\end{array}$ \\
\hline $\begin{array}{l}\text { Roche vd., } \\
2014\end{array}$ & $\begin{array}{c}\text { E-11,10 } \\
\text { E-9,4 }\end{array}$ & Klinik & Araştırmacı & -Talep etme & $\begin{array}{l}\text { Tümünde } \\
\text {-Tek başına }\end{array}$ & $\begin{array}{l}\text { Sözel, } \\
\text { Fiziksel }\end{array}$ & ÇBM & + & - & - & - & - & ++ & $\begin{array}{l}\text { Ed. } 2 / 2 \\
\text { İzl. } 2 / 2\end{array}$ \\
\hline $\begin{array}{l}\text { Xin \& } \\
\text { Leonard, } \\
2015\end{array}$ & $\begin{array}{l}\text { E-10 } \\
\text { E-10 } \\
\text { K-10 }\end{array}$ & Okul & $\begin{array}{l}\text { Yardımcı } \\
\text { Öğretmen }\end{array}$ & $\begin{array}{l}\text {-Talep etme, } \\
\text {-Yanit verme, } \\
\text {-Yorum yapma }\end{array}$ & $\begin{array}{c}\text { Bir kısmında } \\
\text {-Tek başına } \\
\text {-Cihaz } \\
\text { Kullanımı+İGA }\end{array}$ & $\begin{array}{c}\text { İB, } \\
\text { Sözel, } \\
\text { Jest, } \\
\text { Model, } \\
\text { Fiziksel }\end{array}$ & ÇBM & - & - & + & - & - & -- & $\begin{array}{c}\text { Ed. } 3 / 3 \\
\text { Gnl. } 3 / 3\end{array}$ \\
\hline $\begin{array}{l}\text { Ülke- } \\
\text { Kürkçüoğlu, } \\
2015\end{array}$ & $\begin{array}{l}\text { K-6 } \\
\text { E-5 } \\
\text { E-5 }\end{array}$ & Klinik & Araştırmacı & -Oyun becerileri & $\begin{array}{c}\text { Bir kısmında } \\
\text {-Karşılaştırma } \\
\text { (Video Model } \\
\text { ile İGA) }\end{array}$ & $\begin{array}{c}\text { İB, } \\
\text { Jest+Sözel, } \\
\text { Fiziksel+Sözel }\end{array}$ & UDUM & + & + & + & + & $\begin{array}{c}+ \\
\text { (Ebeveyn, } \\
\text { Lisansüstü } \\
\text { Öğrenciler) }\end{array}$ & ++ & $\begin{array}{c}\text { Ed. } 3 / 3 \\
\text { İzl. } 3 / 3 \\
\text { Gnl. } 3 / 3 \\
18 / 18\end{array}$ \\
\hline $\begin{array}{c}\text { Kourassanis } \\
\text { vd., } 2015\end{array}$ & $\begin{array}{l}\text { K-5 } \\
\text { E-6 }\end{array}$ & Klinik & Araştırmacı & -Sosyal oyun & $\begin{array}{l}\text { Bir kısmında } \\
\text {-Tek başına } \\
\text {-Uyarlama } \\
\text { amaçlı }\end{array}$ & $\begin{array}{l}\text { Jest, } \\
\text { Sözel, } \\
\text { KF, TF }\end{array}$ & ÇBM & - & - & - & + & $\begin{array}{c}+ \\
\text { (Ebeveyn) }\end{array}$ & ++ & $\begin{array}{l}\text { Ed. 2/2 } \\
\text { Gnl. 2/2 } \\
\text { SG. 2/2 }\end{array}$ \\
\hline Barton, 2015 & $\begin{array}{c}\mathrm{K}-5,3 \\
\mathrm{~K}-3,10 \\
\mathrm{E}-3,11 \\
\mathrm{E}-5,7 \\
\end{array}$ & Sinif & Öğretmen & $\begin{array}{c}\text {-Oyun becerileri, } \\
\text {-İletişim } \\
\text { başlatma/yanıt } \\
\text { verme }\end{array}$ & $\begin{array}{l}\text { Tümünde } \\
\text { - Davranış1 } \\
\text { İzleyen } \\
\text { Taklit+İGA }\end{array}$ & $\begin{array}{c}\text { İB, } \\
\text { Sözel+model, } \\
\text { TF }\end{array}$ & ÇYM & + & + & + & + & - & ++ & $\begin{array}{c}\text { Ed. 4/4 } \\
\text { İzl. 4/4 } \\
\text { Gnl. 4/4 }\end{array}$ \\
\hline
\end{tabular}


OTIZM SPEKTRUM BOZUKLUĞU OLAN BIREYLERE SOSYAL ETKILESIM VE ILETISISIM BECERILERININ

Tablo 1 (devami)

\begin{tabular}{|c|c|c|c|c|c|c|c|c|c|c|c|c|c|c|}
\hline \multirow[b]{2}{*}{ Kaynak } & \multirow{2}{*}{$\begin{array}{l}\text { Cinsiyet } \\
\text { (Yaş, Ay) }\end{array}$} & \multirow[b]{2}{*}{ Ortam } & \multirow[b]{2}{*}{ Uygulamacı } & \multirow{2}{*}{$\begin{array}{c}\text { Hedef } \\
\text { beceriler }\end{array}$} & \multirow{2}{*}{$\begin{array}{l}\text { İGA kullanım } \\
\text { türü }\end{array}$} & \multirow[b]{2}{*}{ İpucu türleri } & \multirow{2}{*}{$\begin{array}{l}\text { Araştırma } \\
\text { modeli }\end{array}$} & \multirow[b]{2}{*}{ İzl } & \multicolumn{3}{|c|}{ Gnl } & \multirow{2}{*}{\multicolumn{2}{|c|}{$\begin{array}{l}\text { GAG } \\
\text { ve } \\
\text { UG } \\
\end{array}$}} & \multirow[b]{2}{*}{ Bulgular } \\
\hline & & & & & & & & & KA & OA & $\mathrm{AA}$ & & & \\
\hline $\begin{array}{l}\text { Curiel vd., } \\
2016\end{array}$ & E-2,7 & Sinif & Araştırmacı & -Alıcı dil & $\begin{array}{l}\text { Bir kısmında } \\
\text {-Uyarlama } \\
\text { amaçlı İGA }\end{array}$ & $\begin{array}{l}\text { Jest, } \\
\text { Sözel }\end{array}$ & ÇYM & + & - & - & + & $\begin{array}{c}+ \\
\text { Ebeveyn } \\
\text { (İnformal) }\end{array}$ & ++ & $\begin{array}{c}\text { Ed. 1/1 } \\
\text { İzl. 1/1 } \\
\text { Gnl. 1/1 } \\
\text { SG. 1/1 }\end{array}$ \\
\hline $\begin{array}{l}\text { Shillingsburg } \\
\text { \& Cariveau, } \\
2016\end{array}$ & $\begin{array}{l}8 \text { E- 5-9 } \\
\text { K-4 } \\
\text { K-5 }\end{array}$ & - & Araştırmacı & $\begin{array}{c}\text {-Soru sorma, } \\
\text {-Konuyu } \\
\text { değiştirme } \\
\text { - Ayırt etme }\end{array}$ & $\begin{array}{l}\text { Bir kısmında } \\
\text {-Uyarlama } \\
\text { amaçlı İGA }\end{array}$ & - & ÇBM & + & - & - & & $\begin{array}{l}+ \\
(-)\end{array}$ & +- & $\begin{array}{c}\text { Ed. } \\
10 / 10 \\
\text { İzl.0/7 } \\
\text { SG.: - }\end{array}$ \\
\hline $\begin{array}{l}\text { Thiemann- } \\
\text { Bourque vd., } \\
2016\end{array}$ & $\begin{array}{c}\text { E-5,1 } \\
\text { E-3,9 } \\
\text { E-4,7 } \\
\text { K-3 }\end{array}$ & Sinif & Akran & $\begin{array}{c}\text {-İletişim } \\
\text { başlatma, } \\
\text {-Talep etme, } \\
\text {-Yanit verme, } \\
\text {-Nesne } \\
\text { paylaşma }\end{array}$ & $\begin{array}{l}\text { Tümünde, } \\
\text {-PECS+İGA }\end{array}$ & $\begin{array}{c}\text { İB, } \\
\text { Jest, } \\
\text { Jest+jest, } \\
\text { Sözel, } \\
\text { KF }\end{array}$ & $\mathrm{AB}$ & - & + & + & + & - & ++ & $\begin{array}{c}\text { Ed. 4/4 } \\
\text { Gnl. 1/4 }\end{array}$ \\
\hline $\begin{array}{l}\text { Wilson vd., } \\
2017\end{array}$ & E-7 & $\mathrm{Ev}$ & Araştırmacı & $\begin{array}{c}\text {-Oyun } \\
\text { becerileri }\end{array}$ & $\begin{array}{l}\text { Bir kısmında } \\
\text {-Hata } \\
\text { düzeltmesi } \\
\text { amaçlı İGA }\end{array}$ & $\begin{array}{l}\text { İB, } \\
\text { Sözel, } \\
\text { Jest, } \\
\text { TF }\end{array}$ & ÇYM & + & - & - & + & - & ++ & $\begin{array}{l}\text { Ed. 1/1 } \\
\text { İzl. 1/1 } \\
\text { Gnl. 1/1 }\end{array}$ \\
\hline $\begin{array}{l}\text { Alzrayer vd., } \\
2017\end{array}$ & $\begin{array}{l}\text { E-8 } \\
\text { E-9 } \\
\text { E-10 } \\
\text { K-10 }\end{array}$ & Sinif & Araştırmacı & -Talep etme & $\begin{array}{c}\text { Tümünde } \\
\text {-SabitBekleme } \\
\text { SÖ+Ayrımlı } \\
\text { Pekiş̧irme+İGA }\end{array}$ & $\begin{array}{c}\text { Sözel+jest, } \\
\text { KF, } \\
\text { Sözel+fiziksel }\end{array}$ & ÇYM & - & - & - & + & - & ++ & $\begin{array}{c}\text { Ed. } 4 / 4 \\
\text { Gnl. } 4 / 4\end{array}$ \\
\hline $\begin{array}{l}\text { Finke vd., } \\
2017\end{array}$ & $\begin{array}{c}\text { E-12 } \\
\text { K-10 } \\
\text { E-9 } \\
\text { K-13 } \\
\text { E-10 } \\
\text { E-12 } \\
\end{array}$ & Sinif & Araştırmacı & $\begin{array}{l}\text {-Teknolojide } \\
\text { çoklu mesaj } \\
\text { üreterek } \\
\text { iletişim kurma }\end{array}$ & $\begin{array}{l}\text { Tümünde } \\
\text {-İGA }\end{array}$ & $\begin{array}{c}\text { Sözel, } \\
\text { Sözel +model, } \\
\text { Sözel+model+ } \\
\text { Görsel } \\
\text { TF }\end{array}$ & ÇYM & + & - & - & + & - & ++ & $\begin{array}{l}\text { Ed. 6/6 } \\
\text { İzl. 5/6 } \\
\text { Gnl.6/6 }\end{array}$ \\
\hline
\end{tabular}


OTIZM SPEKTRUM BOZUKLUĞU OLAN BIREYLERE SOSYAL ETKILESSIM VE ILLETIŞIM BECERILERİNIN

Tablo 1 (devami)

\begin{tabular}{|c|c|c|c|c|c|c|c|c|c|c|c|c|c|c|}
\hline \multirow{2}{*}{ Kaynak } & \multirow{2}{*}{$\begin{array}{l}\text { Cinsiyet } \\
\text { (Yaş, } \\
\text { Ay) } \\
\end{array}$} & \multirow{2}{*}{ Ortam } & \multirow{2}{*}{ Uygulamac1 } & \multirow{2}{*}{ Hedef beceriler } & \multirow{2}{*}{ İGA kullanım türü } & \multirow{2}{*}{ İpucu türleri } & \multirow{2}{*}{$\begin{array}{l}\text { Araştırma } \\
\text { modeli }\end{array}$} & \multirow{2}{*}{ İzl } & \multicolumn{3}{|c|}{ Gnl } & \multirow{2}{*}{ SG } & \multirow{2}{*}{$\begin{array}{l}\text { GAG } \\
\text { ve } \\
\text { UG } \\
\end{array}$} & \multirow{2}{*}{ Bulgular } \\
\hline & & & & & & & & & KA & $\mathrm{OA}$ & $\mathrm{AA}$ & & & \\
\hline $\begin{array}{l}\text { D'Agostino } \\
\text { vd., } 2018\end{array}$ & $\begin{array}{l}\text { E-4 } \\
\text { E-4 } \\
\text { E-5 }\end{array}$ & Klinik & Araştırmacı & $\begin{array}{l}\text {-Yorum yapma, } \\
\text {-Yanit verme }\end{array}$ & $\begin{array}{c}\text { Tümünde } \\
\text {-İGA }\end{array}$ & $\begin{array}{l}\text { Görsel+Jest, } \\
\text { KF, TF }\end{array}$ & ÇBM & + & - & - & + & $\begin{array}{c}+ \\
\text { (Okulöncesi } \\
\text { ve } \\
\text { özel eğitim } \\
\text { öğretmen- } \\
\text { leri) }\end{array}$ & ++ & $\begin{array}{c}\text { Ed. } 3 / 3 \\
\text { İzl. } 3 / 3 \\
\text { Gnl. } 3 / 3 \\
\text { SG. } \\
\text { 10/10 }\end{array}$ \\
\hline $\begin{array}{l}\text { Hansen vd., } \\
2018\end{array}$ & $\begin{array}{l}\text { K-4,9 } \\
\text { E-3,1 } \\
\text { E-5,5 }\end{array}$ & Klinik & Ebeveyn & -Ortak dikkat & $\begin{array}{c}\text { Tümünde } \\
\text {-İGA }\end{array}$ & $\begin{array}{c}\text { Sözel, } \\
\text { Sözel+jest, } \\
\text { KF+jest+sözel } \\
\text { TFl+jest+sözel }\end{array}$ & ÇBM & + & - & - & - & - min & ++ & $\begin{array}{l}\text { Ed. 3/3 } \\
\text { İzl. 3/3 }\end{array}$ \\
\hline $\begin{array}{l}\text { Quigley vd., } \\
2018\end{array}$ & $\begin{array}{c}\text { E-8 } \\
\text { K-10 } \\
\text { K-12 }\end{array}$ & Sinif & Araştırmac1 & $\begin{array}{c}\text {-Oyun } \\
\text { becerileri }\end{array}$ & $\begin{array}{c}\text { Bir kısmında } \\
\text {-Karşılaştırma (Model } \\
\text { olma +İGA) }\end{array}$ & $\begin{array}{l}\text { Sözel, } \\
\text { Jest, } \\
\text { TF }\end{array}$ & DUM & - & - & - & - & - & ++ & Ed. $0 / 3$ \\
\hline $\begin{array}{l}\text { Barton vd., } \\
2018\end{array}$ & $\begin{array}{c}\mathrm{K}-3,10 \\
\mathrm{~K}-5,1 \\
\mathrm{~K}-4,4 \\
\mathrm{E}-2,11\end{array}$ & Klinik & Araştırmacı & $\begin{array}{c}\text {-Oyun } \\
\text { becerileri, } \\
\text {-Sosyal iletişim } \\
\text { (ör. yorum } \\
\text { yapma, yanit } \\
\text { verme, vs.) } \\
\text {-Ortak dikkat }\end{array}$ & $\begin{array}{c}\text { Tümünde } \\
\text { - Etkinlik } \\
\text { Çiz.+Pekiştirme+Model } \\
\text { olma }+ \text { İGA }\end{array}$ & $\begin{array}{c}\text { İB, } \\
\text { Jest, } \\
\text { Model+sözel }\end{array}$ & ÇYM & + & - & - & + & - & ++ & $\begin{array}{c}\text { Ed. 4/4 } \\
\text { İzl. 4/4 } \\
\text { Gnl. 4/4 }\end{array}$ \\
\hline $\begin{array}{l}\text { Walsh vd., } \\
2018\end{array}$ & $\begin{array}{l}\text { K-21 } \\
\text { E-20 } \\
\text { E-22 } \\
\text { K-20 } \\
\text { E-22 } \\
\text { E-19 } \\
\text { K-19 }\end{array}$ & Klinik & Öğretmen & $\begin{array}{l}\text {-İşe yerleştirme } \\
\text { için gerekli } \\
\text { sosyal iletişim } \\
\text { becerileri }\end{array}$ & $\begin{array}{l}\text { Bir kısmında } \\
\text {-Hata düzeltmesi } \\
\text { amaçlı İGA }\end{array}$ & $\begin{array}{c}\text { Jest, } \\
\text { Sözel, } \\
\text { Görsel, } \\
\text { Model, } \\
\text { Fiziksel }\end{array}$ & ÇYM & + & + & + & + & $\begin{array}{c}+ \\
\text { (Katılımc1, } \\
\text { Ebeveyn, } \\
\text { Öğretmen) }\end{array}$ & ++ & $\begin{array}{c}\text { Ed. 7/7 } \\
\text { İzl. 7/7 } \\
\text { Gnl. 7/7 } \\
\text { SG. } \\
21 / 21\end{array}$ \\
\hline Ninci vd., 2018 & $\begin{array}{l}\text { E-5 } \\
\text { E-5 } \\
\text { E-7 }\end{array}$ & Klinik & Araştırmacı & $\begin{array}{l}\text {-Alicı dil, } \\
\text {-Talep etme }\end{array}$ & $\begin{array}{l}\text { Bir kısmında } \\
\text {-Hata düzeltmesi } \\
\text { amaçlı İGA }\end{array}$ & $\begin{array}{c}\text { Jest, } \\
\text { Fiziksel }\end{array}$ & UDUM & - & - & - & + & - & ++ & $\begin{array}{c}\text { Ed. 2/3 } \\
\text { Gnl. 2/3 }\end{array}$ \\
\hline
\end{tabular}


OTIZM SPEKTRUM BOZUKLUĞU OLAN BIREYLERE SOSYAL ETKILESSIM VE ILLETIŞIM BECERILERİNIN

Tablo 1 (devami)

\begin{tabular}{|c|c|c|c|c|c|c|c|c|c|c|c|c|c|c|}
\hline \multirow{2}{*}{ Kaynak } & \multirow{2}{*}{$\begin{array}{l}\text { Cinsiyet } \\
\text { (Yaş, Ay) }\end{array}$} & \multirow{2}{*}{ Ortam } & \multirow{2}{*}{ Uygulamac1 } & \multirow{2}{*}{$\begin{array}{c}\text { Hedef } \\
\text { beceriler }\end{array}$} & \multirow{2}{*}{$\begin{array}{l}\text { İGA kullanım } \\
\text { türü }\end{array}$} & \multirow{2}{*}{ İpucu türleri } & \multirow{2}{*}{$\begin{array}{c}\text { Araştırma } \\
\text { modeli }\end{array}$} & \multirow{2}{*}{ İzl } & \multicolumn{3}{|c|}{ Gnl } & \multirow{2}{*}{\multicolumn{2}{|c|}{$\begin{array}{l}\text { GAG } \\
\text { ve } \\
\text { UG }\end{array}$}} & \multirow{2}{*}{ Bulgular } \\
\hline & & & & & & & & & KA & $\mathrm{OA}$ & $\mathrm{AA}$ & & & \\
\hline $\begin{array}{l}\text { Armendariz \& } \\
\text { Hahs, } 2019\end{array}$ & $\begin{array}{l}\text { E-9 } \\
\text { K-6 } \\
\text { E-2 }\end{array}$ & Ev & Araştırmacı & $\begin{array}{c}\text {-Etkinlik } \\
\text { tamamlama, } \\
\text {-Etkileşim } \\
\text { başlatma }\end{array}$ & $\begin{array}{l}\text { Bir kısmında } \\
\text {-Hata düzeltmesi } \\
\text { amaçlı İGA }\end{array}$ & $\begin{array}{l}\text { Jest, } \\
\text { TF }\end{array}$ & ÇBM & + & - & - & - & - & +- & $\begin{array}{l}\text { Ed. 1/3 } \\
\text { İzl. 0/2 }\end{array}$ \\
\hline \multirow[t]{2}{*}{$\begin{array}{l}\text { Barton vd., } \\
2019^{a}\end{array}$} & $\mathrm{~K}-3$ & Sinif & Araştırmacı & $\begin{array}{c}\text {-Oyun } \\
\text { becerileri }\end{array}$ & $\begin{array}{c}\text { Tümünde } \\
\text {-Pekiştirme+İGA }\end{array}$ & $\begin{array}{l}\text { İB, } \\
\text { Model, } \\
\text { TF }\end{array}$ & $\mathrm{ABCBCC}$ & - & - & - & - & - & ++ & Ed. 1/1 \\
\hline & $\mathrm{K}-3$ & Sinıf & $\begin{array}{l}\text { Lisansüstü } \\
\text { öğrencileri }\end{array}$ & $\begin{array}{c}\text {-Oyun } \\
\text { becerileri }\end{array}$ & $\begin{array}{c}\text { Tümünde } \\
\text {-Pekiştirme+İGA }\end{array}$ & $\begin{array}{l}\text { İB, } \\
\text { Model, } \\
\text { TF }\end{array}$ & ÇYM & + & - & - & + & - & ++ & $\begin{array}{l}\text { Ed. 1/1 } \\
\text { İzl. 0/1 } \\
\text { Gnl. 1/1 }\end{array}$ \\
\hline $\begin{array}{l}\text { Hansen vd., } \\
2019\end{array}$ & $\begin{array}{c}\text { E-5 } \\
\text { K-4 } \\
\text { E-4,1 } \\
\text { E-4,2 } \\
\text { E-4,5 } \\
\text { E-4 } \\
\text { E-4,4 }\end{array}$ & Sinıf & $\begin{array}{l}\text { Araştırmac1, } \\
\text { Akran }\end{array}$ & -Ortak dikkat & $\begin{array}{c}\text { Tümünde } \\
\text {-Pekiştirme+İGA }\end{array}$ & $\begin{array}{c}\text { Sözel, } \\
\text { Jest+sözel, } \\
\text { KF+sözel } \\
\text { TF }\end{array}$ & ÇBM & - & - & - & - & $\stackrel{+}{\stackrel{+}{\text { Öğretmen }}}$ & ++ & $\begin{array}{l}\text { Ed. 7/7 } \\
\text { SG. 7/7 }\end{array}$ \\
\hline $\begin{array}{l}\text { Raulston vd., } \\
2019\end{array}$ & $\begin{array}{l}\text { E-6,1 } \\
\text { K-3,5 } \\
\text { E-6,4 }\end{array}$ & Ev & Ebeveyn & -Talep etme & $\begin{array}{c}\text { Tümünde, } \\
\text {-Sosyal } \\
\text { öykü+Etkinlik } \\
\text { Çiz.+Milieu+İGA }\end{array}$ & $\begin{array}{c}\text { Sözel, } \\
\text { Sözel }+ \text { model }\end{array}$ & ÇYM & + & - & - & - & $\begin{array}{c}+ \\
\text { Ebeveyn }\end{array}$ & ++ & $\begin{array}{l}\text { Ed. } 3 / 3 \\
\text { İzl. } 3 / 3 \\
\text { SG. } 3 / 3\end{array}$ \\
\hline $\begin{array}{l}\text { Schaefer- } \\
\text { Whitby vd., } \\
2019\end{array}$ & $\mathrm{~K}-7$ & Klinik & Araştırmacı & -Talep etme & $\begin{array}{c}\text { Tümünde, } \\
\text {-PECS+İGA }\end{array}$ & $\begin{array}{l}\text { İB, } \\
\mathrm{KF}, \mathrm{TF}\end{array}$ & $\mathrm{AB}$ & - & - & - & - & - & -- & Ed. 1/1 \\
\hline $\begin{array}{l}\text { Alzrayer vd., } \\
2020\end{array}$ & $\begin{array}{l}\text { E-8 } \\
\text { E-5 } \\
\text { K-6 }\end{array}$ & Sinıf & Araştırmacı & -Talep etme & $\begin{array}{c}\text { Tümünde } \\
\text {-Artan Bek. Sür. } \\
\text { Öğr.+Sözel } \\
\text { ipucu+Ayrımlı } \\
\text { Pekiştirme+İGA }\end{array}$ & $\begin{array}{l}\text { Sözel, } \\
\text { Jest, } \\
\text { KF }\end{array}$ & ÇYM & + & + & + & - & $\begin{array}{c}+ \\
\text { (Öğretmen, } \\
\text { Yardımcı } \\
\text { öğretmen }\end{array}$ & ++ & $\begin{array}{c}\text { Ed. 3/3 } \\
\text { İzl. 3/3 } \\
\text { Gnl. 3/3 }\end{array}$ \\
\hline
\end{tabular}


OTIZM SPEKTRUM BOZUKLUĞU OLAN BIREYLERE SOSYAL ETKILEȘIM VE ILETISSTIM BECERILERININ

Tablo 1 (devamı)

\begin{tabular}{|c|c|c|c|c|c|c|c|c|c|c|c|c|c|c|}
\hline \multirow{2}{*}{ Kaynak } & \multirow{2}{*}{$\begin{array}{l}\text { Cinsiyet } \\
\text { (Yaş, Ay) }\end{array}$} & \multirow{2}{*}{ Ortam } & \multirow{2}{*}{ Uygulamac1 } & \multirow{2}{*}{$\begin{array}{c}\text { Hedef } \\
\text { beceriler }\end{array}$} & \multirow{2}{*}{$\begin{array}{l}\text { İGA kullanım } \\
\text { türü }\end{array}$} & \multirow{2}{*}{ İpucu türleri } & \multirow{2}{*}{$\begin{array}{l}\text { Araştırma } \\
\text { modeli }\end{array}$} & \multirow{2}{*}{ İzl } & \multicolumn{3}{|c|}{ Gnl } & \multirow{2}{*}{\multicolumn{2}{|c|}{$\begin{array}{l}\text { GAG } \\
\text { ve } \\
\text { UG }\end{array}$}} & \multirow{2}{*}{ Bulgular } \\
\hline & & & & & & & & & KA & OA & AA & & & \\
\hline $\begin{array}{l}\text { Queiroz vd., } \\
2020\end{array}$ & $\begin{array}{l}\text { E-7 } \\
\text { E-7 }\end{array}$ & $\begin{array}{c}\text { Okul } \\
\text { kütüphanesi }\end{array}$ & Araştırmacı & $\begin{array}{l}\text { Sözel ve } \\
\text { sözel } \\
\text { olmayan } \\
\text { iletişim } \\
\text { başlatma }\end{array}$ & $\begin{array}{l}\text { Tümünde } \\
\text {-Tek başına }\end{array}$ & $\begin{array}{c}\text {-Sözel (Soru } \\
\text { tekrarı) } \\
\text {-Kısmi Model } \\
\text { (Sorunun } \\
\text { cevabının } \\
\text { kısmen } \\
\text { söylenmesi) } \\
\text {-Model } \\
\text { (sorunun } \\
\text { cevabının tam } \\
\text { olarak } \\
\text { söylenmesi) }\end{array}$ & ÇBM & - & - & - & + & $\begin{array}{c}+ \\
\text { (Öğretmen, } \\
\text { Aileler) }\end{array}$ & ++ & $\begin{array}{c}\text { Ed. 1/2 } \\
\text { Gen. 1/2 } \\
\text { SG. +/? }\end{array}$ \\
\hline $\begin{array}{l}\text { Erturk vd., } \\
2020\end{array}$ & $\begin{array}{l}\text { E-4,2 } \\
\text { E-4,3 }\end{array}$ & $\mathrm{Ev}$ & Anne & $\begin{array}{l}\text { Sosyal } \\
\text { iletişim }\end{array}$ & $\begin{array}{c}\text { Tümünde } \\
\text {-Koçluk+İGA }\end{array}$ & $\begin{array}{c}\text {-İB, } \\
\text {-Sözel, } \\
\text {-KF+sözel } \\
\text {-TF }\end{array}$ & ÇBM & + & - & - & + & - & ++ & $\begin{array}{c}\text { Ed. 2/2 } \\
\text { Gen. 2/2 } \\
\text { İzl. 2/2 }\end{array}$ \\
\hline
\end{tabular}

Not: AA = araçlar arası, ÇBM = çoklu başlama modeli, ÇYM = çoklu yoklama modeli, DUM = dönüşümlü uygulamalar modeli, E = erkek, Ed = edinim, GAG = gözlemciler arası güvenirlik, Gnl = genelleme, İzl = izleme, $\mathrm{K}=\mathrm{kız}, \mathrm{KA}=$ kişiler arası, $\mathrm{KF}=$ kısmi fiziksel, $\mathrm{OA}=$ ortamlar arası, $\mathrm{SG}=$ sosyal geçerlik, $\mathrm{UDUM}=$ uyarlamalı dönüşümlü uygulamalar modeli, $\mathrm{UG}=$ uygulama güvenirliği, $\mathrm{TF}=$ tam fiziksel, $-=$ belirtilmemiş. ${ }^{a}$ Çalışma kendi içinde Çalışma I ve Çalışma II diye ayrılmış̧ır. 
Araştırmaların beşinde ise çalışmanın yalnızca ev ortamında gerçekleştirildiği rapor edilmiştir (Armendariz \& Hahs, 2019; Erturk vd., 2020; Raulston vd., 2019; Topuz \& Ülke-Kürkçüoğlu, 2019; Wilson vd., 2017). İki araştırmada ise hem sınıfta hem evde uygulamanın yürütüldüğü görülmüştür (Cannella-Malone vd., 2010; Van Der Meer vd., 2013).

\section{Araștırma Modeli}

$\mathrm{Bu}$ çalışma kapsamına dahil edilen araştırmalar incelendiğinde, 35 araştırmadan 14'ünde (ör. Huskens vd., 2013; Waddington vd., 2014) tek denekli araştırma modellerinden çoklu başlama düzeyi modeli, 12 araştırmada ise (ör. Barton, 2015; Curiel vd., 2016) çoklu yoklama modeli kullanılmıştır. Araştırmaların ikisinde tek denekli araştırma modelleri içinde en zayıf deneysel kontrol sağlanan model olan AB modeli kullanılmıştır (Schaefer-Whitby vd., 2019; Thiemann-Bourque vd., 2016). Bir araştırmada da ABAB modeli tercih edilirken (Kern vd., 2007), başka bir araştırmada değişen ölçütler modeli kullanılmıştır. Araştırma kapsamında İGA'nın başka uygulamalarla karşılaştırıldığı dört araştırmada dönüşümlü (Quigley vd., 2018; Van Der Meer vd., 2013) ya da uyarlamalı dönüşümlü uygulamalar modeli kullanılmıştır (Ninci vd., 2018; Ülke-Kürkçüoğlu, 2015). Bir araştırmada ise çoklu uygulama modellerinden ABCBCC modeli kullanılmıştır (Barton vd., 2019).

\section{Bağımlı Değișkenler}

Araştırma kapsamında incelenen araştırmaların 21'inde bir bağımlı değişken, geriye kalan araştırmalarda da iki ve daha fazla bağımlı değişken üzerinde çalışılmıştır. Araştırmalarda tek bağımlı değişken üzerindeki etkililik çalışmalarında talep etme (Alzyrayer vd., 2017; Alzyrayer vd., 2019; Lund \& Troha, 2008; Raulston vd., 2019; Roche vd., 2014; Schaefer-Whitby vd., 2019), soru sorma (Huskens vd., 2013), oyun (Barton vd., 2019; Kourassanis vd., 2015; Ülke-Kürkçüoğlu, 2015, Quigley vd., 2018,), alıcı dil (Curiel vd., 2016), ortak dikkat (Hansen vd., 2018; Hansen vd., 2019), yardımcı teknolojiyle çoklu mesaj üreterek iletişim kurma (Finke vd., 2017), işe yerleştirmek için gerekli sosyal iletişim (Walsh vd., 2018), sosyal iletişim (Erturk vd., 2020) ve iletişim başlatma (Charlop \& Greenberg, 2009; Queiroz vd., 2020) becerilerinin öğretimi gerçekleştirilmiştir.

Araştırmaların dokuzunda eş zamanlı olarak sosyal etkileşim ve iletişim becerileri olarak selamlama ve el sallama (Thiemann \& Goldstein, 2004), talep etme ve teşekkür etme (Waddington vd., 2014), oyun ve iletişim becerileri (Barton, 2015; Barton vd., 2018), yorum yapma ve yanit verme (D’Agostino vd., 2018), alıc1 dil ve talep etme (Ninci vd., 2018), iletişim başlatma ve genişletme (Topuz \& Ülke-Kürkçüoğlu, 2019) becerileri üzerinde çalışılmıştır. Araştırmaların geri kalanında ise üç ila beş bağımlı değişken üzerindeki etkililik incelenmiştir. Üç bağımlı değişkenin ele alındığı araştırmalarda; göz kontağı, oyuncak paylaşma ve sohbeti başlatma-sürdürme (Tetreault \& Lerman, 2010), talep etme, yanit verme ve selamlama/yorum yapma (Cannella-Malone vd., 2010; Xin \& Leonard, 2015), soru sorma, konuyu değiştirme ve ilgili-ilgisiz ayırımı yapma (Shillingsburg \& Cariveau, 2016) becerileri üzerinde çalışılmıştır.

Araştırmaların üçünde ise üçten daha fazla bağımlı değişken üzerindeki etkililik incelenmiştir. Bu araştırmaların hepsinde yanıt verme becerisinin yanı sıra dikkat yöneltme, yorum yapma, övme ve istek bildirme (Thiemann \& Goldstein, 2004), talep etme, selamlama ve nezaket bildirme (Van Der Meer vd., 2013), iletişim başlatma, talep etme ve nesne paylaşma (Thiemann-Bourque vd., 2016) becerilerinin de öğretimi gerçekleştirilmiş̧tir.

\section{Bağımsız Değişken Olarak İGA Öğretiminin Kullanım Biçimi}

Araştırmalar incelendiğinde, bağımsız değişken olarak İGA'nın, 35 araştırmadan 19'unda araştırmaların tümünde kullanıldığı görülmektedir. Araştırmaların geri kalanlarında $(n=16)$ ise İGA'nın araştırmaların bir kısmında kullanıldığı dikkat çekmektedir. İGA'nın araştırmanın tümünde kullanıldı̆̆ çalışmalar derinlemesine incelendiğinde, 13 araştırmada yöntemin başka uygulama(lar) ya da teknik(ler) ile birlikte kullanıldığı (ör. Kern vd., 2007; Ülke-Kürkçüoğlu, 2015); altı araştırmada yöntemin tek başına etkisinin sınandığı (ör. Roche vd., 2014) görülmüştür. Yöntemin başka bir uygulama/teknik ile birlikte kullanıldığı araştırmalarda, İGA şarkı (Kern vd., 2007), PECS (Cannella-Malone vd., 2010; Schaefer-Whitby vd., 2019, Thiemann-Bourque vd., 2016), davranış1 izleyen taklit (Barton, 2015), sabit bekleme süreli öğretim ve ayrımlı pekiştirme (Alzrayer vd., 2017), etkinlik çizelgesi, pekiştirme ve model olma (Barton vd., 2018), pekiştirme (Barton vd., 2019; Hansen vd., 2019), sosyal öykü, etkinlik çizelgesi ve milieu öğretimi (Raulston vd., 2019) ve artan bekleme süreli öğretim, ipucu ve ayrımlı pekiştirme (Alzrayer vd., 2020) ve koçluk uygulaması (Erturk vd., 2020) ile birlikte sunulmuştur.

İGA’nın araştırmanın bir kısmında kullanıldığı çalışmalar derinlemesine incelendiğinde, yöntemin tüm araştırmalarda tek başına kullanıldığı dikkat çekmektedir. Bu bağlamda, İGA araştırmalarda hata düzeltmesi 
amaçlı (Armendariz \& Hahs, 2019; Ninci vd., 2018; Thiemann \& Goldstein, 2004; Walsh vd., 2018; Wilson vd., 2017), replik öğretimi (Charlop \& Greenberg, 2009; Topuz \& Ülke-Kürkçüoğlu, 2019), uyarlama (Curiel vd., 2016; Kourassanis vd., 2015; Shillingsburg \& Cariveau, 2016; Tetreault \& Leerman, 2010), alternatif destekleyici iletişim cihazı kullanımını öğretme (Van Der Meer vd., 2013; Waddington vd., 2014; Xin \& Leonard, 2015) amaçlı kullanılmıştır. Son olarak, yalnızca bir araştırmada yöntemin video modelle öğretimle (Ülke-Kürkçüoğlu, 2015); bir diğer araştırmada ise, model olma ve model olma + İGA ile etkililiğinin ve verimliliğinin karşılaştırıldığı görülmüştür (Quigley vd., 2018).

\section{IGA Sunulurken Kullanılan İpucu Türleri ve Hiyerarşisi}

Araştırma kapsamına alınan ve İGA sunulan araştırmalarda uygulama sırasında farklı ipucu türlerinden oluşan bir ipucu hiyerarşisinin kullanıldığı görülmüştür. Yalnızca iki araştırmada, İGA sunulurken kullanılan ipucu türlerine ilişkin bilgilere rastlanmamıştır (Charlop \& Greenberg, 2009; Shillingsburg \& Cariveau, 2016). Araştırmaların dördünde sözel-fiziksel ya da jest-sözel ipuçlarından oluşan ikili ipucu hiyerarşisinin kullanıldığı (Armendariz \& Hahs, 2019; Curiel vd., 2016; Ninci vd., 2018; Roche vd., 2014), diğer araştırmalarda üçlü, dörtlü ve beşli ipucu hiyerarşisinin kullanıldığı dikkat çekmektedir (Cannella-Malone vd., 2010; Lund \& Troha, 2008; Xin \& Leonard, 2015). Araştırmaların 16'sında (ör. Barton vd., 2018; Huskens vd., 2013; Lund \& Troha, 2008; Schaefer-Whitby vd., 2019) ipucu hiyerarşisinin ilk basamağı olarak ipucundan bağımsız olmaya ve diğer basamaklarda ise sözel, fiziksel vb. ipucu türlerine yer verilmiştir. Bununla birlikte bir ipucu hiyerarşisinde jest + sözel, fiziksel + sözel ya da sözel + model ipuçlarından oluşan iki ipucunun, hiyerarşinin bir ya da iki basamağını oluşturduğu görülmüştür (Alzrayer vd., 2017; Barton, 2015; Tetreault \& Lerman, 2010; Thiemann-Bourque vd., 2016; Ülke-Kürkçüoğlu, 2015; Waddington vd., 2014). Örneğin, Ülke-Kürkçüoğlu (2015) tarafından üçlü ipucu hiyerarşisi olarak ipucundan bağımsız, sözel + jestsel, sözel + fiziksel ipuçları kullanılmıştır. İkinci ve üçüncü basamaklarda iki ipucu türüne birlikte yer verilmiştir.

Araştırma kapsamına dahil edilen araştırmaların 16'sında üçlü ipucu hiyerarşisi kullanılmıştır (ör. Alzrayer vd., 2020; Van Der Meer vd., 2013). Üçlü ipucu hiyearşisi kullanılırken bu 16 araştırmanın 11 'inde ipucu hiyerarşisindeki her bir basamakta bir ipucu türüne rastlanmış (ör. Huskens vd., 2013; Quigley vd., 2018; Topuz \& Kürkçüoğlu, 2019; Wilson vd., 2017); ancak, geri kalan araştırmalarda (ör. Barton, 2015; Barton vd., 2018; D’Agostino vd., 2018; Tetreault \& Lerman, 2010) basamaklardan en az birinde iki ipucu türünün birlikte kullanıldığ 1 görülmüştür. Örneğin, Barton vd. (2018) tarafından ipucu hiyerarşisinin birinci basamağında ipucundan bağımsız, ikinci basamağında jest ipucu, üçüncü basamağında ise model +sözel ipucu kullanılmıştır.

\section{İzleme Verileri}

Araştırma sonlandırıldıktan sonra yöntemin etkililiğini belirlemek amacıyla yapılan izleme çalışmalarına ilişkin olarak, 35 araştırmanın 23'ünde izleme çalışmasının yürütüldüğü (ör. Armendariz \& Hash, 2019; Walsh vd., 2018; Raulston vd., 2019); ancak geriye kalan 12 araştırmada (ör. Hansen vd., 2019; Schaefer-Whitby vd., 2019) izleme oturumlarına yer verilmediği görülmüştür. İki farklı çalışmanın birlikte rapor edildiği Barton vd. (2019) araştırmasında bir çalışmada izleme verilerinin toplandığı; diğer çalışmada ise izleme çalışmasına yer verilmediği görülmüştür.

\section{Genelleme Verileri}

Araştırmalar; farklı kişiler, farklı araç-gereçler ve farklı ortamlar arasında yapılan genelleme çalışmalarına göre incelendiğinde, araştırmaların 21'inde genelleme çalışmasının yürütüldüğü görülmüştür. Ancak, 14 araştırmada genelleme verilerine ilişkin bulguya rastlanmamıştır. Barton ve diğerleri (2019) yürüttüğü iki çalışmadan biri olan lisansüstü öğrencilerin uygulamacı olduğu çalışmada araçlar arası genelleme oturumlarının düzenlendiği dikkat çekmektedir. Araştırmaların birinde kişilerarası genelleme oturumları düzenlenmiştir (Waddington vd., 2014). Araştırmaların 14'ünde araçlar arası genelleme çalışılırken (ör. Charlop \& Greenberg, 2009; Tetreault \& Lerman, 2010); birinde ortamlar arası genelleme oturumlarının yürütüldüğü göze çarpmaktadır (Xin \& Leonard, 2015). Araştırmaların yalnızca birinde hem kişiler hem de ortamlar arası genelleme çalışmasına yer verildiği görülmüştür (Alzrayer vd., 2020). Araştırmaların beşinde kişiler, ortamlar ve araçlar arası olmak üzere üç farklı genelleme türü çalışılmıştır (Barton, 2015; Thiemann-Bourque vd., 2016; Topuz \& ÜlkeKürkçüoğlu, 2019; Ülke-Kürkçüoğlu, 2015; Walsh vd., 2018).

\section{Sosyal Geçerlik Verileri}

Araştırmalar incelendiğinde 35 araştırmanın 15 'inde sosyal geçerlik verilerinin toplandığ $\breve{g}, 20$ araştırmada sosyal geçerlik çalışmasına ilişkin herhangi bir bulgunun rapor edilmediği görülmüştür. Sosyal geçerlik çalışması 
yürütülen araştırmalardan yalnızca birinde araştırmaya katılan katılımcılardan veri toplanmıştır (Van Der Meer vd., 2013). 15 araştırmanın dördünde ise anne-babalardan sosyal geçerlik verisi toplanırken; üç araştırmada öğretmenlerden veri toplanmıştır. D’agostino ve diğerleri (2018) tarafından yürütülen araştırmanın sosyal geçerlik çalışmasında hem okulöncesi hem de özel eğitim öğretmenlerinden görüş alındığı rapor edilirken; Alzrayer ve diğerleri (2020) öğretmenden ve yardımcı öğretmenden görüş aldıklarını belirtmiştir. Araştırmaların birinde ögrretmen ve lisansüstü öğrencilerden (Thiemann \& Goldstein, 2004), ikisinde hem anne-babalardan hem öğretmenlerden (Cannella-Mallone vd., 2010; Queiroz vd., 2020) ve bir başka araştırmada anne-babalardan ve lisansüstü öğrencilerden görüş alındığı rapor edilmiştir (Ülke-Kürkçüoğlu, 2015). Son olarak, bir araştırmada, katılımcıların ve sınıftaki diğer öğrencilerin anne ve babalarından, bakıcılarından ve sınıf öğretmenlerinden sosyal geçerlik verisi toplandığı rapor edilmiştir; ancak, kaç kişiden veri toplandiğı belirtilmemiştir (Kern vd., 2007). Sosyal geçerlik çalışması olan araştırmalardan farklı olarak Walsh ve diğerleri (2018) tarafından yürütülen çalışmada katılımcılardan, anne-babalardan ve öğretmenlerden olmak üzere üç farklı gruptan veri toplanmıştır. Ancak Shillingsburg ve Cariveau (2016) çalışmasında sosyal geçerlik verisinin toplandığ 1 belirtilmesine rağmen bu verilerin kimlerden toplandığına ilişkin bir bilgi rapor edilmemiştir.

\section{Uygulama Güvenirliği ve Gözlemciler Arası Güvenirlik Verileri}

Araştırmalar incelendiğinde, iki çalışma dışında (Schaefer-Whitby vd., 2019; Xin \& Leonard, 2015) diğer çalışmaların tümünde $(n=33)$ gözlemcilerarası güvenirlik verilerinin toplandığı dikkat çekmektedir. Araştırmalar uygulama güvenirliği açısından incelendiğinde, dört çalışma dışında (Armendariz \& Hahs, 2019; Schaefer-Whitby vd., 2019; Shillingsburg \& Cariveau, 2016; Xin \& Leonard, 2015) diğer çalışmaların tamamında $(n=31)$ uygulama güvenirliği verisinin toplandığı görülmüştür. İki araştırmada ise hem gözlemciler arası hem de uygulama güvenirliği verisinin toplanmadığı dikkat çekmektedir (Schaefer-Whitby vd., 2019; Xin \& Leonard, 2015).

\section{Araştırmaların Bulguları}

Araştırma kapsamındaki 35 araştırmanın bulgusu incelenmiştir. Bu bulgular edinim, izleme, genelleme ve sosyal geçerlik olarak ayrı başlıklar altında ele alınmıştır.

\section{Edinim}

Araştırmaların 29'unda araştırmacılar İGA'nın tek başına ya da farklı bir uygulamayla birlikte kullanıldığında tüm katılımcıların hedeflenen becerileri edinmelerinde etkili olduğunu göstermiştir. Ancak yalnızca Quigley ve diğerleri (2018) tarafından yürütülen araştırmada model olma ve İGA birlikte kullanılmasına rağmen tüm katılımcıların; Erturk ve diğerleri (2020) tarafından yürütülen ve İGA'nın tek başına kullanıldığı araştırmada ise, iki katılımcıdan birinin hedeflenen becerileri edinemediği rapor edilmiştir. Ayrıca İGA'nın hata düzeltmesi amaçlı kullanıldığı iki çalışmadan biri olan Armendariz ve diğerlerinin (2019) çalışmasında üç katılımcıdan ikisinin; Ninci ve diğerlerinin (2018) çalışmasında üç katılımcıdan birinin hedeflenen becerileri edinemediği belirtilmiştir. İGA’nın uyarlama amaçlı kullanıldığı bir çalışmada ise üç katılımcıdan ikisinin edinim sağlayamadıği sonucuna ulaşılmıştır (Tetreault \& Lerman, 2010).

\section{İzleme}

İzleme verisi toplanan 23 araştırmanın 17'sinde katılımcıların edinim düzeyinde kazandıkları becerileri koruyabildikleri (ör. Alzrayer vd., 2020; Walsh vd., 2018); ancak, üç araştırmada katılımcıların hiçbirinin edindikleri becerileri koruyamadıkları rapor edilmiştir (Armendariz \& Hahs, 2019; Barton vd., 2019; Shillingsburg \& Cariveau, 2016). Finke ve diğerleri (2017) ise İGA sunulduğunda edinim sağlanmasına rağmen altı katılımcıdan birinin edindiği beceriyi koruyamadığı belirtilmiştir. Ayrıca Barton ve diğerlerinin (2019) iki çalışmasından birinde İGA ve pekiştirme sunularak hedef becerinin öğretildiği; ancak, katılımcının bu beceriyi koruyamadığ rapor edilmiştir.

\section{Genelleme}

Genelleme verisi toplanan 22 çalışmadan üçünde İGA sunularak hedeflenen becerileri genelleyemeyen katılımcıların olduğu rapor edilmiştir. Bu çalışmalardan biri Thieman-Bourque ve diğerleri (2016) tarafından gerçekleştirilmiştir ve çalışmada dört katılımcının üçünün edindiği becerileri genelleyemediği belirtilmiştir. Ek olarak Ninci ve diğerleri (2018) üç katılımcıdan birinin; Erturk ve diğerleri (2020) ise iki katılımcıdan birinin genellemeyi gerçekleştiremediğini çalışmalarında rapor etmişlerdir. 


\section{Sosyal Geçerlik}

Sosyal geçerlik çalışmasının yürütüldüğü 14 araştırmanın 12'sinde sosyal geçerlik verisi toplanan bireylerin tamamının araştırma sürecindeki uygulamalara ilişkin olumlu görüş bildirdiği rapor edilmiştir (ör. Curiel vd., 2016; Hansen vd., 2019; Ülke-Kürkçüoğlu, 2015; Van Der Meer vd., 2013). Thiemann ve Goldstein (2004) tarafından yürütülen bir araştırmada sosyal geçerlik verisinin toplandığı öğretmenlerden ve lisansüstü öğrencilerden oluşan 21 bireyden yalnızca 18'inin olumlu görüş bildirdiği belirtilmiştir. Alzrayer ve diğerleri (2020) ve Erturk ve diğerleri (2020) çalışmasında ise sosyal geçerlik verilerinin olumlu yönde olduğu belirtilmiş; ancak kaç bireyden veri toplandığına ilişkin bilgi rapor edilmemiştir. Bir başka araştırmada da sosyal geçerlik verisi toplandığı ifade edilmesine rağmen bu veriye ilişkin bulgulardan söz edilmemiştir (Shillingsburg \& Cariveau, 2016).

\section{Tartışma}

Bu çalışmada, 2003-2020 yılları arasında OSB olan çocuklara çeşitli sosyal beceri öğretiminde yanlışsız öğretim yöntemlerinden İGA öğretiminin sunulmasıyla yürütülen araştırmalar demografik özellikler, yöntemsel parametreler ve araştırmalardan elde edilen bulgular açısından betimsel olarak analiz edilmiştir. Araştırma kapsamına alınan araştırmalardaki katılımcıların demografik özellikleri incelendiğinde, İGA sunulan araştırmaların katılımcılarının yaklaşık yarısına yakınının $(n=51)$ 2-5 yaş okulöncesi dönem çocuklarından ve yarısının $(n=53)$ 6-13 yaş aralığındaki okul dönemi çocuklarından oluştuğu görülmektedir. Her ne kadar katılımcıları yalnızca OSB tanılı bireylerden oluşmasa da, Shepley ve diğerleri (2019) çalışmasında katılımcıların çoğunlukla 6-12 yaş aralığında olduğu görülmektedir. Ancak farklı olarak bu çalışmada, özellikle 14-17 yaş (Cannella-Malone vd., 2010; Lund \& Troha, 2008) ve 18-21 yaş aralığında (ör. Walsh vd., 2018) katılımcılarla yürütülen araştırmaların sınırlı sayıda olduğu dikkat çekmektedir. Dolayısıyla 14-21 yaş aralığındaki katılımcılara sosyal etkileşim ve iletişim becerilerinin öğretiminde İGA öğretiminin etkililiğini sınayan araştırmalara gereksinim olduğu öne sürülebilir. Ayrıca cinsiyet açısından araştırmalar ele alındığında, araştırmalarda yalnızca kızların, yalnızca erkeklerin yanı sıra hem kız hem de erkek katılımcıların birlikte yer aldığı görülmektedir. Bu araştırmalarda kız katılımcıların sayıca az olması, OSB tanısının erkeklerde yaklaşık beş kat fazla görülmesi nedeniyle beklenen bir sonuçtur. Dört çalışma dişında (Armendariz \& Hahs, 2019; Ninci vd., 2018; Quigley vd., 2018; Tetreault \& Lerman, 2010) hem kızların hem erkeklerin katılımcı olduğu diğer çalışmalarda tüm deneklerin edinim sağlaması, cinsiyet farkı gözetmeksizin İGA öğretiminin etkili olarak kullanıldığını göstermektedir.

Araştırmalarda İGA öğretimi sunan uygulamacılar incelendiğinde, 11 araştırma dışında diğerlerinde araştırmacıların kendisinin uygulamacı olduğu görülmektedir (ör. Schaefer-Whitby vd., 2019). 11 araştırma içinde de Shepley ve diğerlerinin çalışmasındaki bulgulara benzer olarak çoğunlukla öğretmenler uygulamacı olmuştur; ancak, sınırlı sayıda araştırmada anneler ve akranlar uygulamacı olarak yer almıştır. Örneğin, bir araştırmada uygulamacı olarak yalnızca akran yer alırken (Thiemann-Bourque vd., 2016), bir diğer araştırmada hem akran hem de araştırmacı uygulamayı yürütmüştür (Hansen vd., 2019). Ayrıca üç araştırmada da yalnızca ebeveyn tarafından uygulama gerçekleştirilmiştir (Hansen vd., 2018; Raulston vd., 2019). Ancak kardeşlerin uygulamacı görevini üstendiği hiçbir araştırmaya rastlanmamıştır. Dolayısıyla gelecekte ebeveyn ve akranların uygulamacı olduğu araştırmalara devam edilirken; kardeşlerin de uygulama yürüttüğü araştırmaların tasarlanması önerilebilir.

Araştırmalarda uygulama sürecinin gerçekleştiği ortamlar ele alındığında, 35 çalışmanın 16' sının okulda (ör. Barton, 2015; Charlop \& Greenberg, 2009; Hansen vd., 2019) beşinin evde (ör. Armendariz \& Hahs, 2019), ikisinin de hem ev hem sinıf (Cannella-Malone vd., 2010; Van Der Meer vd., 2013) ortamında yürütüldüğü görülmektedir. Benzer biçimde Shepley vd. (2019) çalışmasında ise 123 araştırmanın çoğunun okul ortamında (n $=65)$ gerçekleştiği, ev $(n=13)$, klinik $(n=8)$ ve toplumsal ortamlarda $(n=10)$ daha az çalışmanın yürütüldüğü rapor edilmektedir. Bu bulgular 1şı̆̆ında toplumsal ve ev ortamlarında tasarlanmış araştırmalara hiç ya da yeteri kadar rastlanmaması nedeniyle ileri araştırmalarda bağımsız yaşam ve genelleme için gerekli olan alışveriş merkezi, market vb. toplumsal ortamlarda ve evde İGA öğretiminin etkililiğinin sorgulandığı araştırmaların yürütülmesi alanyazını genişletmek açısından yararlı olabilir.

İGA öğretiminin etkililiğine yönelik araştırmalarda, araştırma modeli olarak çoklu başlama ve yoklama modellerinin daha çok tercih edildiği görülmektedir. Ek olarak araştırma kapsamında İGA'nın başka uygulamalarla karşılaştırıldığı dört çalışmada dönüşümlü, uyarlamalı dönüşümlü uygulamalar ya da $\mathrm{ABCBCC}$ modelinin kullanıldığı görülmektedir (Barton vd., 2019; Topuz \& Ülke-Kürkçüoğlu, 2019; Van Der Meer vd., 2013). Bu çalışmayla tutarlı olarak Shepley ve diğerlerinin çalışmasında da araştırmacıların, etkililik araştırmalarında çoğunlukla çoklu yoklama ve başlama modellerini, karşılaştırma araştırmalarında ise dönüşümlü ve bağımsız değişkenin geriye çekildiği modelleri tercih ettikleri görülmektedir. Dolayısıyla etkililik ya da 
karşılaştırma araştırmaları için alanyazında mevcut kullanılan araştırma modelleri dışındaki modeller kullanılarak da İGA öğretiminin etkililiğini ve verimliliğini sorgulayan araştırmaların yürütülmesi önerilebilir.

Araştırmalardaki bağımlı değişkenler ele alındığında en güncel çalışmaların sosyal iletişim ve etkileşim becerileri içinde ortak dikkat (Hansen, 2019), talep etme (Raulston vd., 2019), oyun becerileri (Barton vd., 2019); etkileşim başlatma (Queiroz vd., 2020) becerilerine odaklandığı göze çarpmaktadır. Tüm araştırmalarda beceriler arasında talep etme ve oyun becerilerinin sıklıkla öğretildiği; ancak ortak dikkat, göz kontağı, oyuncak paylaşımı, sohbet başlatma-sürdürme, soru sorma-yanıtlama ve yorum yapma becerilerinin sınırlı sayıdaki araştırmalarda öğretildiği görülmektedir. Bu durum bir yandan, araştırmacıların bağımsız tepki verme firsatı sunarak hata oranını arttırma riskine karşı İGA'yı daha az tercih etmelerinden kaynaklanmış olabilir. Diğer yandan da araştırmacıların talep etme ve oyun becerileri için bağımsız tepki fırsatı sunmanın gerekliliği düşüncesi İGA kullanma eğilimini arttırmış olabilir. Ayrıca Shepley ve diğerleri (2019) tarafından İGA öğretiminin sunulduğu araştırmalarda, tek basamaklı becerilere (\%44.7) göre zincirleme becerilerin (\%55.3) daha fazla çalışıldığı rapor edilmektedir. Ancak bu becerilerin içinde de oyun ve boş zaman becerilerinin (\%13) yanı sıra sosyal ve iletişim becerilerinin (\%10.6) toplumsal yaşam, mesleki, bilişsel ve akademik becerilere (\%63.4) göre daha az öğretildiği belirtilmektedir. Bu bulguya benzer olarak konuya ilişkin daha önceki araştırmalarda da İA öğretimi ile pek çok sosyal etkileşim ve iletişim becerisinin yeterli düzeyde çalışılmadığı görülmektedir (Shepley vd., 2019). Dolayısıyla ileri araştırmalarda İGA öğretiminin sözü edilen becerilerin öğretimi üzerine odaklanması yararlı olabilir.

Araştırma kapsamına alınan çalışmalarda uygulama sürecinde İGA'nın tek başına ve başka uygulamalarla birlikte araştırmaların tümünde kullanıldığ 1 yanı sıra hata düzeltmesi, uyarlama gibi amaçlarla araştırmaların bir kısmında kullanıldığı görülmektedir. Ancak yalnızca İGA sunumuyla sosyal etkileşim ve iletişim becerilerinin öğretiminde etkililik sorgulayan araştırmaların sınırlı sayıda (ör. Roche vd., 2014) olduğu dikkat çekmektedir. Bununla birlikte yalnızca bir araştırmada İGA öğretiminin tek başına kullanılarak video modelle etkililik ve verimlilik açısından karşılaştırıldığı görülmektedir (Ülke-Kürkçüoğlu, 2015). Shepley ve diğerlerinin (2019) çalışmasında da bu bulgulara benzer olarak 123 araştırmanın 77'sinde İGA öğretiminin araştırmanın tümünde tek başına, 30'unun bir öğretim paketinin bir parçası olarak, 14'ünün video modelle/video ipucuyla birlikte kullanıldığı rapor edilmektedir. Ek olarak incelenen beş araştırmadan ikisinin tekli ipucu yöntemleri (ör. sabit bekleme süreli öğretim) ve üçünün tek olmayan ipucu yöntemleriyle (ör. aşamalı yardımla, ipucunun giderek azaltılması ve video modelle öğretim) karşılaştırıldığı rapor edilmektedir. Her iki derleme çalışmasındaki bulgulardan yola çıkılarak İGA'nın tekli olan ve olmayan diğer yöntemlerle sınırlı sayıda etkililik ve verimliliğinin karşılaştırıldığı görülmektedir. Dolayısıyla, ileri araştırmalarda sosyal etkileşim ve iletişim becerilerinin yanı sıra diğer becerilerin öğretiminde İGA’nın farklı uygulamalarla karşılaştırıldığı çalışmaların yürütülmesi önerilebilir.

Araştırmalarda İGA sunulurken kullanılan ipucu türleri incelendiğinde, sınırlı sayıda araştırmada $(n=4)$ ikili ipucu hiyerarşisinin kullanıldığ 1 (Armendariz \& Hahs, 2019; Curiel vd., 2016; Ninci vd., 2018; Roche vd., 2014), diğer araştırmalarda üçlü, dörtlü ve beşli ipucu hiyerarşisine yer verildiği dikkat çekmektedir (CannellaMalone vd., 2010; Lund \& Troha, 2008; Xin \& Leonard, 2015). Ancak araştırmacıların çoğunlukla $(n=16)$ üçlü ipucu hiyerarşisini tercih ettiği, seçtikleri becerilere ve katılımcıların özelliklerine göre de her bir basamakta ipuçlarını tek başına ya da bir başka ipucu türüyle birlikte kullandıkları görülmektedir. İpucu türleri olarak da jest, sözel, model ve fiziksel ipuçlarına yer verildiği; ancak, görsel ipucunun son yıllarda yürütülen yalnızca iki araştırmada yer aldığı dikkat çekmektedir (D’Agostino vd., 2018; Walsh vd., 2018). Bu çalışmadan farklı olarak Shepley ve diğerleri (2019) inceledikleri araştırmalarda ipucu türlerini, kontrol edici ipucu olması açısından ayrı olarak ele almaktadır. Ancak çalışmalarında ipucu hiyerarşisinde her bir basamakta yer alan ipuçlarının özelliklerine ilişkin bir bilgi rapor etmemektedirler. Ayrıca kontrol edici ipucu olarak ipucu türleri içinde fiziksel ipucundan sonra model ipucunun kullanıldığı; ancak, görsel ipucunun hiç kullanılmadığı da dikkat çekmektedir. Dolayısıyla gelecek araştırmalarda görsel ipucunun da yer aldığı farklı ipucu kombinasyonlarının kullanıldı ̆̆ araştırmaların tasarlanması İGA'nın etkili kullanımına ilişkin alanyazını desteklemesi açısından yararlı olabilir. Ayrıca araştırmaların yaklaşık üçte birinde ipucu hiyerarşisindeki ilk basamağın ipucundan bağımsız ipucu düzeyi olduğu görülmektedir. Araştırmacıların da talep etme, soru sorma, yanıt verme, yorum yapma ve oyun becerilerinin öğretiminde ipucu hiyerarşisinin ilk basamağı olarak ipucundan bağımsız olmayı tercih ettikleri göze çarpmaktadır (ör. Huskens vd., 2013; Lund \& Troha, 2008). Özellikle bu becerilerde ipucundan bağımsız olmanın tercih edilmesinin nedeni, yetişkin yönlendirmesi olmadan bağımsız tepki firsatı vererek ve hata olasılığını göze alarak becerilerin doğasına uygun bir biçimde öğretilmesini sağlamak olabilir. Dolayısıyla ileride konuya ilişkin araştırmalarda, ipucundan bağımsız ipucu düzeyinin ipucu hiyerarşisinin ilk basamağı olduğu ve olmadığı araştırmalardaki hata oranları incelenerek daha gerçekçi bulgulara ulaşılabilir. 
Shepley ve diğerleri (2019) tarafından araştırmaların kalıcılık, genelleme ve sosyal geçerlik açısından incelendiğine dair bir bilgiye rastlanmamaktadır. Ancak bu araştırmada kapsam içine alınan araştırmalar kalıcılık, genelleme ve sosyal geçerlik bulguları açısından ele alınmaktadır. Bu araştırmaların edinim sağlanan becerilerdeki kalıcılık dikkate alındığında, yalnızca 23'ünde izleme oturumlarına yer verildiği ve 20 çalışmada tüm katılımcılarda edinilen becerilerin korunduğu görülmektedir. Ancak izleme verisi olan üç araştırmada katılımcıların hiçbirinin edindikleri becerileri koruyamadıkları dikkat çekmektedir (Armendariz \& Hahs, 2019; Barton vd., 2019; Shillingsburg \& Cariveau, 2016). Bu çalışmalardan yalnızca birinde becerilerin kalıcılığının sağlanamamasının nedeni açıklanmıştır (Barton vd., 2019). Barton ve diğerleri, bu durumun katılımcının performans düzeyinin yalnızca pekiştirme ve ipucu sunulduğunda artmasından kaynaklandığını rapor etmişlerdir. Araştırmacılar, ileri araştırmalarda dikkatli gözlemlerle ve veriye dayalı kararlar alınarak öncelikle ipuçlarının ardından pekiştireçlerin sistematik bir şekilde silikleştirilmesi gerektiğini vurgulamışlardır. Dolayısıyla konuya ilişkin ileri araştırmalarda, edinim sürecinde ipuçlarına ve pekiştireçlerin silikleştirilmesine dikkat edilerek kalıcılığın sağlanıp sağlanmadığını belirlemek amacıyla kalıcılığın farklı zamanlarda da sınanmasına özen gösterilmelidir.

Araştırmaların çoğunlukla $(n=21)$ genelleme çalışmasına yer verdiği; ancak beş araştırmada kişiler, ortamlar ve araçlar arası olmak üzere üç farklı genelleme türüne ilişkin veri toplandığı görülmektedir (Barton, 2015; Thiemann-Bourque vd., 2016; Topuz \& Ülke-Kürkçüoğlu, 2019; Ülke-Kürkçüoğlu, 2015; Walsh vd., 2018). Genelleme çalışması yürüten araştırmalardan elde edilen bulgular incelendiğinde, birinde dört katılımcıdan üçünün; bir diğerinde üç katılımcıdan birinin ve bir diğerinde iki katılımcıdan birinin genellemeyi sağlayamadığı dikkat çekmektedir (Erturk vd., 2020; Ninci vd., 2018; Thieman-Bourque vd., 2016). Dolayısıyla ileri araştırmalarda genelleme çalışmalarına ağırlık verilerek farklı türlerin bir arada çalışıldığı genelleme oturumlarının düzenlenmesi önerilebilir. Ek olarak edinim sürecinde genellemenin de aralıklarla sınandığ 1 ve edinilen becerilerde genelleme sağlandıktan sonra genellemenin kalıcılığının sağlanıp sağlanmadığının da incelenmesi alanyazını genişletmek açısından yararlı olabilir.

Araştırmaların üçte birinden fazlasında $(n=15)$ öznel değerlendirme türünde sosyal geçerlik çalışmasının yürütüldüğü ve sosyal geçerlik verilerinin çoğunlukla öğretmen, anne-baba ve lisansüstü öğrencilerden görüş alınarak toplandığ1 görülmektedir (ör. Alzrayer vd., 2020; Cannella-Mallone vd., 2010; D’agostino vd., 2018; Thiemann \& Goldstein, 2004). Bir araştırmada ise katılımcıların kendilerinden görüş alındığı rapor edilmektedir (Van Der Meer vd., 2013). Bu bireylerin görüşlerinin çoğunlukla İGA öğretimine ya da İGA öğretiminin de içinde yer aldığı uygulamaya ilişkin olumlu olduğu belirtilmektedir. Bu durum, sosyal geçerlik açısından İGA öğretiminin ilgili bireyler için yararlı olduğunu göstermektedir. Ancak bu araştırma dişında örneğin Walsh ve diğerlerinin yürüttüğü çalışmasındaki gibi katılımcıların sözel ifade becerisine sahip olmasına rağmen bu yönde bir sosyal geçerlik çalışmasının yürütülmediği görülmektedir. Gelecek çalışmalarda, ilgili bireylerin yanı sıra özellikle katılımcıların kendi beceri düzeylerine göre yürütülen uygulamaya ilişkin görüşlerinin alınmasına önem verilmelidir. Katılımcılardan görüş almanın mümkün olmadığı durumlarda da sosyal karşılaştırma çalışmalarının yürütülmesi önerilebilir.

Araştırmaların 14'ünde edinim, izleme ve genelleme çalışmasının üçüne birden yer verildiği göze çarpmaktadır. $\mathrm{Bu}$ nedenle ileri araştırmalarda daha fazla bu üç verinin bir arada toplandığı araştırmaların yürütülmesi önerilebilir. Ayrıca yalnızca altı araştırmada (ör. Van Der Meer vd., 2013; Curiel vd., 2016) bulgu olarak bu üç verinin toplanmasının yanı sıra sosyal geçerlik verisinin de toplandığı rapor edilmektedir. Gelecek araştırmalarda, edinim, izleme ve genelleme ile birlikte sosyal geçerlik çalışmalarına da ağırlık verilmesi, araştırma sürecindeki uygulamaların sosyal kabul düzeyini ortaya koyarak daha nitelikli çalışmaların yürütülmesi açısından yararlı olabilir.

Araştırmalarda hem gözlemciler arası güvenirliğin $(n=33)$ hem de uygulama güvenirliğinin neredeyse tüm araştırmalarda $(n=31)$ önemsendiği görülmektedir. Bu bulgu İGA ile yürütülen araştırmaların güvenilir bir biçimde uygulandığını göstermektedir. Benzer olarak Shepley ve diğerlerinin (2019) çalışmasında da her iki güvenirlik türüne ilişkin bulgular incelenmiştir. Araştırma kapsamına alınması için bir araştırmada en az \%80 düzeyinde uygulama güvenirliği verisinin rapor edilmesi ölçütü aranmıştır. İleri araştırmalarda da güvenirlik konusuna olan özenin devam etmesi yararlı olacaktır.

Araştırma kapsamında değerlendirilen çalışmalar, hedeflenen becerilerin edinimi açısından ele alındığında, 117 katılımcıdan yalnızca onunun edinim sağlayamadığı görülmektedir (Armendariz \& Hahs, 2019; Erturk vd., 2020; Lund \& Troha, 2008; Ninci vd., 2018; Tetreault \& Lerman, 2010). Kat1lımc1ların 107'sinin hedeflenen becerileri edinmesi, İGA'nın araştırmaların tümünde ya da bir kısmında kullanılmasıyla etkili 
sonuçlara ulaşıldığını göstermektedir. Edinim sağlanan becerilerde izleme ve genelleme çalışması yürüten araştırmalar incelendiğinde, katılımcıların çoğunun hem becerileri koruduğu hem de genellemeyi sağladığ görülmektedir. Shepley ve diğerlerinin (2019) çalışmasında orta ve güçlü etki olarak sınıflandırdıkları araştırmalara göre 13 yaşında ya da daha büyük bireylere toplumsal, özbakım ve mesleki becerilerin öğretiminde İGA'nın etkili olarak kullanılabileceği belirtilmektedir. Ek olarak aynı çalışmada 13 yaşından küçük özel gereksinimli bireylere diğer becerilerin öğretiminde İGA'nın kullanılmasının yararlı olacağı; ancak hata yüzdesinin artma olasılığının verimliliği düşürebileceği vurgulanmaktadır. Hata yüzdesinin diğer yanlışsız öğretim yöntemlerine göre daha fazla olduğu, daha önce yanlışsız öğretim yöntemlerinin karşılaştırıldığı araştırmaları inceleyen bir derleme çalışmasında da vurgulanmaktadır (Ault vd., 1989). Dolayısıyla sözü edilen çalışmaların yanı sıra bu çalışmanın bulguları ışığında alanda çalışan uzmanlara, ailelere ve uygulamacılara sosyal iletişim ve etkileşim becerilerinin öğretiminde İGA'nın etkili bir uygulama olarak kullanılması; ancak hata yüzdesinin artma olasılığının dikkate alınması önerilebilir.

$\mathrm{Bu}$ araştırmada, bulgulara ilişkin bazı sınırlılıklar bulunmaktadır. Birincisi, çalışmaların tamamı yerine yalnızca \%50'sine ilişkin güvenirlik verisi toplanmıştır. İleri araştırmalarda çalışmaların tamamına ilişkin güvenirlik verisi toplanması çalışmanın güvenirliğini arttırması açısından yararlı olabilir. İkincisi Barton ve diğerlerinin (2019) iki çalışmanın bir makalede rapor edildiği araştırmasında ele alınan veriler ayrı olarak incelenmiştir. Örneğin, 3 yaşında bir kız çocuğuna oyun becerileri ayrı olarak öğretilmiştir. Dolayısıyla araştırmanın birinde araştırma modeli olarak çoklu yoklama modeli kullanılmış; bir diğerinde ABCBCC modeli kullanılmıştır. Bu çalışmalar tek makalede rapor edildiği için araştırma sayısı bir olarak ele alınmıştır. Ancak farklılaşan veriler (araştırma modeli, uygulamacı, izleme, genelleme) ayrı ayrı değerlendirilmiştir. Üçüncüsü bu çalışmada belirli anahtar kelimeler kullanarak dört farklı veri tabanı taranmış; ancak, hakemli dergilerin kendi içinde tek tek elle tarama yapılmamıştır. İleri araştırmalarda daha fazla sayıda hem ulusal hem de uluslararası veri tabanları kullanılarak gelişmiş arama yapılmasının yanı sıra kaynakçalardan yola çıkılarak elle tarama yapılması önerilebilir. Ayrıca ulusal alanyazında yürütülen lisansüstü tez çalışmaları da araştırma kapsamına alınabilir. Ek olarak İGA'ya ilişkin çalışmalar OSB olan bireylerle, sosyal iletişim ve sosyal etkileşim becerilerinin öğretimiyle sınırlı değildir. Farklı araştırmalarda diğer gelişimsel yetersizlik grubundaki bireylere çeşitli becerilerin öğretiminde İGA kullanımının incelendiği derleme çalışmaları da yürütülebilir.

Çalışma dahil etme ve hariç tutma ölçütlerine göre kapsama alınarak belirlenen tek denekli araştırmalar ile sınırlıdır. Ancak, tek denekli her bir modele ilişkin niteliksel veriler incelenerek ve etki büyüklükleri belirlenerek bir karşılaştırma yapılmamıştır. Shepley ve diğerleri (2019) çalışmasında ise What Works Clearinghouse kılavuzu kullanılarak araştırmaların niteliğinin sorgulandığı; ancak etki büyüklüklerine ilişkin bir incelemenin yapılmadığı görülmektedir. Dolayısıyla ileri araştırmalarda konuya ilişkin araştırmaların etki büyüklüklerini ortaya koyan ve karşılaştıran metaanaliz çalışmalarının yapılması önerilebilir.

Alanyazında, İGA'nın verimliliğinin diğer tek ipuçlu yanlışsız öğretim stratejilerine göre düşük olmasına rağmen farklı tanı ve yaş gruplarındaki öğrencilere çeşitli becerilerin öğretiminde kullanıldığı, öğretmen yetiştirme programlarında önerildiği ve özel eğitim öğretmenleri tarafından yaygın olarak tercih edildiği görülmektedir (ör. Barton \& Wolery, 2008; Shepley vd., 2019). Ülkemizde ise İGA'nın kullanıldığı araştırmaların sayısı sınırlı da olsa günden güne artmaktadır (Bilmez, 2014; Kurnaz, 2018; Saral \& Ülke-Kürkçüoğlu, 2020; Topuz \& ÜlkeKürkçüoğlu, 2019; Ülke-Kürkçüoğlu, 2015; Yanardağ vd., 2011). Bu çalışmalarda da İGA'nın sunumuyla OSB olan bireylere oyun, replik, ortak dikkat ve motor beceriler gibi becerilerin etkili biçimde öğretildiği görülmektedir. Dolayısıyla öğretmenlerin ve uygulamacıların öğretimdeki parametreleri (öğrenci özellikleri, ortam, uygulama vb.) dikkate alarak İGA’yı da alternatif bir öğretim yöntemi olarak kullanmaları önerilebilir.

\section{Yazarların Katkı Düzeyleri}

Birinci yazar, araştırmanın tasarlanmasında görev almıştır. Araştırmaya ilişkin makaledeki giriş, yöntem, bulgular ve tartışma bölümünü yazmıştır. İkinci yazar araştırmaya dahil edilen çalışmaların belirlenebilmesi amacıyla alanyazın taraması gerçekleştirmiş, ulaşılan araştırmaların betimsel analiz tablosuna kodlanmasında görev almıştır.

\section{Teşekkür}

Arş. Gör. Çetin Topuz'a araştırmanın kodlayıcılar arası güvenirlik verilerinin hesaplanmasında görev aldığı için teşekkür ederiz. 


\section{Kaynaklar}

Ahlgrim-Delzell, L., Browder, D. M., \& Wood, L. (2014). Effects of systematic instruction and an augmentative communication device on phonics skills acquisition for students with moderate intellectual disability who are nonverbal. Education and Training in Autism and Developmental Disabilities, 49(4), 517-532. https://www.jstor.org/stable/pdf/24582348.pdf

Aljehany, M. S., \& Bennet, K. (2019). A comparison of video prompting to least-to-most prompting among children with autism and intellectual disability. Journal of Autism and Developmental Disorders, Advance Online Publication. https://doi.org/10.1007/s10803-019-03929-x

Alzrayer, N. M., Banda, D. R., \& Koul, R. (2017). Teaching children with autism spectrum disorder and other developmental disabilities to perform multistep requesting using an iPad. Augmentative and Alternative Communication, 33(2), 65-76. https://doi.org/10.1080/07434618.2017.1306881

Alzrayer, N. M., Muharib, R., \& Wood, C. (2020). Effects of a behavior intervention package on augmented and vocal mands by children with developmental disabilities. Journal of Developmental and Physical Disabilities, 32(1), 57-74. https://doi.org/10.1007/s10882-019-09681-5

American Psychiatric Association. (2013). Diagnostic and statistical manual of mental disorders (5th ed.). American Psychiatric Publishing.

Armendariz, V., \& Hahs, A. D. (2019). Teaching leisure activities with social initiations through video prompting. Journal of Behavioral Education, 28(4), 479-492. https://doi.org/10.1007/s10864-019-09320-1

Ault, M. J., \& Griffen, A. K. (2013). Teaching with the system of least prompts: An easy method for monitoring progress. Teaching Exceptional Children, 45(3), 46-53. https://doi.org/10.1177/004005991304500305

Ault, M. J., Wolery, M., Doyle, P. M., \& Gast, D. L. (1989). Review of comparative studies in instruction of students with moderate and severe handicaps. Exceptional Children, 55(4), 346-356. https://doi.org/10.1177/001440298905500410

Barton, E. E. (2015). Teaching generalized pretend play and related behaviors to young children with disabilities. Exceptional Children, 81(4), 489-506. https://doi.org/10.1177/0014402914563694

Barton, E. E., \& Pavilanis, R. (2012). Teaching pretend play to young children with autism. Young Exceptional Children, 15(1), 5-17. https://doi.org/10.1177/1096250611424106

Barton, E. E., Gossett, S., Waters, M. C., Murray, R., \& Francis, R. (2019). Increasing play complexity in a young child with autism. Focus on Autism and Other Developmental Disabilities, 34(2), 81-90. https://doi.org/10.1177/1088357618800493

Barton, E. E., Pokorski, E. A., Sweeney, E. M., Velez, M., Gossett, S., Qiu, J., Flaherty, C., \& Domingo, M. (2018). An empirical examination of effective practices for teaching board game play to young children. Journal of Positive Behavior Interventions, 20(3), 138-148. https://doi.org/10.1177/1098300717753833

Barton, E. E., \& Wolery, M. (2008). Teaching pretend play to children with disabilities: A review of the literature. Topics in Early Childhood Special Education, 28(2), 109-125. https://doi.org/10.1177/0271121408318799

Barton, E. E., \& Wolery, M. (2010). Training teachers to promote pretend play in young children with disabilities. Exceptional Children, 77(1), 85-106. https://doi.org/10.1177/001440291007700104

Bilmez, H. (2014). Otizm spektrum bozukluğu olan çocuklara ortak dikkate tepki verme becerisinin öğretimi [Teaching joint attention skills to chidlren with autsim spectrum disorders] (Tez Numaras1: 375289) [Yüksek lisans tezi, Anadolu Üniversitesi]. Yükseköğretim Kurulu Ulusal Tez Merkezi.

Bouck, E. C., Savage, M., Meyer, N. K., Taber-Doughty, T., \& Hunley M. (2014). High-tech or low-tech? Comparing self-monitoring systems to increase task independence for students with autism. Focus on Autism and Other Developmental Disabilities, 29(3), 156-167. https://doi.org/10.1177/1088357614528797 

ÖĞRETIMMINDE İPUCUNUN GIDEREK ARTTIRILMASI: SISTEMATIKK BİR DERLEME

Browder, D. M., Jimenez, B. A., Spooner, F., Saunders, A., Hudson, M., \& Bethune, K. S. (2012). Early numeracy instruction for students with moderate and severe developmental disabilities. Research and Practice for Persons with Severe Disabilities, 37(4), 308-320. https://doi.org/10.2511/027494813805327205

Cannella-Malone, H. I., Chan, J. M., \& Jimenez, E. D. (2017). Comparing self-directed video prompting to leastto-most prompting in post-secondary students with moderate intellectual disabilities. International Journal of Developmental Disabilities, 63(4), 211-220. https://doi.org/10.1080/20473869.2017.1301695

Cannella-Malone, H. I., Fant, J. L., \& Tullis, C. A. (2010). Using the picture exchange communication system to increase the social communication of two individuals with severe developmental disabilities. Journal of Developmental and Physical Disabilities, 22(2), 149-163. https://doi.org/doi:10.1007/s10882-009-9174$\underline{4}$

Charlop, M. H., \& Greenberg, A. L. (2009). Implementing visual strategies during play groups: The promising effects on social communication skills for children with autism. Evidence-Based Communication Assessment and Intervention, 3(3), 168-173. https://doi.org/10.1080/17489530903343382

Curiel, E. S., Sainato, D. M., \& Goldstein, H. (2016). Matrix training of receptive language skills with a toddler with autism spectrum disorder: A case study. Education and Treatment of Children, 39(1), 95-109. https://muse.jhu.edu/article/612001

D’Agostino, S. R., Dueñas, A. D., \& Plavnick, J. B. (2018). Increasing social initiations during shared book reading: An intervention for preschoolers with autism spectrum disorder. Topics in Early Childhood Special Education, 39(4), 213-225. https://doi.org/10.1177/0271121418816422

DiCarlo, C. F., \& Reid, D. H. (2004). Increasing pretend toy play of toddlers with disabilities in an inclusive setting. Journal of Applied Behavior Analysis, 37(2), 197-207. https://doi.org/doi:10.1901/jaba.2004.37$\underline{197}$

Doyle, P. M., Wolery, M., Ault, M. J., \& Gast, D. L. (1988). System of least prompts: A literature review of procedural parameters. Journal of the Association for Persons with Severe Handicaps, 13(1), 28-40. https://doi.org/10.1177/154079698801300104

Ergin, G. (2017). Otizm spektrum bozukluğu olan çocukların hayali oyun davranışlarının çeşitlendirilmesinde ipucunun giderek arttırlmasıyla ögretimin etkililiği [The effectiveness of least to most prompting procedure teaching strategy in varying pretend play behaviours of children with autism spectrum disorders] (Tez Numaras1: 463465) [Yüksek lisans tezi, Anadolu Üniversitesi]. Yükseköğretim Kurulu Ulusal Tez Merkezi.

Erturk, B., Hansen, S. G., Machalicek, W., \& Kunze, M. (2020). Parent-implemented early social communication intervention for young children with autism spectrum disorder. Journal of Behavioral Education, Advance Online Publication. https://doi.org/10.1007/s10864-020-09387-1

Filla, A., Wolery, M., \& Anthony, L. (1999). Promoting children's conversations during play with adult prompts. Journal of Early Intervention, 22(2), 93-108. https://doi.org/10.1177/105381519902200201

Finke, E. H., Davis, J. M., Benedict, M., Goga, L., Kelly, J., Palumbo, L., Peart, T., \& Waters, S. (2017). Effects of a least-to-most prompting procedure on multisymbol message production in children with autism spectrum disorder who use augmentative and alternative communication. American Journal of SpeechLanguage Pathology, 26(1), 81-98. https://doi.org/10.1044/2016_AJSLP-14-0187

Gıc1-Vatansever, A. (2018). Otizm spektrum bozukluğuna sahip çocuğu olan annelere sunulan koçluk uygulamalarının annelerin ögretim becerilerini ve çocukların ortak dikkate tepki verme becerilerini edinmeleri üzerinde etkileri [The effects of coaching mothers of children with autism spectrum disorder on their teaching skills and on their children's acquisition of responding to joint attention skills] (Tez Numarası: 511171) [Doktora tezi, Trakya Üniversitesi]. Yükseköğretim Kurulu Ulusal Tez Merkezi.

Hansen, S. G., Raulston, T. J., Machalicek, W., \& Frantz, R. (2018). Caregiver-mediated joint attention intervention. Behavioral Interventions, 33(2), 205-211. https://doi.org/10.1002/bin.1523 
Hansen, S. G., Raulston, T. J., Machalicek, W., Frantz, R., Drew, C., Erturk, B., \& Squires, J. (2019). Peermediated joint attention intervention in the preschool classroom. The Journal of Special Education, 53(2), 96-107. https://doi.org/10.1177/0022466918807464

Huskens, B., Verschuur, R., Gillesen, J., Didden, R., \& Barakova, E. (2013). Promoting question-asking in schoolaged children with autism spectrum disorders: Effectiveness of a robot intervention compared to a humantrainer intervention. Developmental Neurorehabilitation, 16(5), 345-356. https://doi.org/10.3109/17518423.2012.739212

Kern, P., Wolery, M., \& Aldridge, D. (2007). Use of songs to promote independence in morning greeting routines for young children with autism. Journal of Autism and Developmental Disorders, 37(7), 1264-1271. https://doi.org/doi:10.1007/s10803-006-0272-1

Kourassanis, J., Jones, E. A., \& Fienup, D. M. (2015). Peer-video modeling: Teaching chained social game behaviors to children with ASD. Journal of Developmental and Physical Disabilities, 27(1), 25-36. https://doi.org/doi:10.1007/s10882-014-9399-8

Kurnaz, E. (2018). Otizmli bireylere karşıllklı konuşma sırasında kullanılan ortak dikkat davranışlarının ögretiminde ipucunun giderek artırlmaslyla ögretimin etkililiği [Effects of system of least in teaching joint attention skills to individuals with autism during conversation] (Tez Numaras1: 525422) [Doktora tezi, Anadolu Üniversitesi]. Yükseköğretim Kurulu Ulusal Tez Merkezi.

Libby, M., Weiss, J. S., Bancroft, S., \& Ahearn, W. H. (2008). A comparison of most-to-least and least-to-most prompting on the acqusition of solitary play skills. Behavior Analysis in Practice, 1, 37-43. https://doi.org/10.1007/BF03391719

Lund, S. K., \& Troha, J. M. (2008). Teaching young people who are blind and have autism to make requests using a variation on the Picture Exchange Communication System with tactile symbols: A preliminary investigation. Journal of Autism and Developmental Disorders, 38(4), 719-730. https://doi.org/10.1007/s10803-007-0439-4

Maenner, M. J., Shaw, K. A., Baio, J., Washington, A., Patrick, M., DiRienzo, M., Christensen, D. L., Wiggins, L. D., Pettygrove, S., Andrews, J. G., Lopez, M., Hudson, A., Baroud, T., Schwenk, Y., White, T., Rosenberg, C. R., Lee, L. C., Harrington, R. A., Huston, M., . . Dietz, P. M. (2020). Prevalence of autism spectrum disorder among children aged 8 years-Autism and developmental disabilities monitoring network, 11 sites, United States, 2016, MMWR Surveillance Summary 2020, 69(6), 1-23. https://doi.org/10.15585/MMWR.SS6904A1

Matson, J. L., Matson, M. L., \& Rivet, T. T. (2007). Social-skills treatments for children with autism spectrum disorders: An overview. Behavior Modification, 31(5), 682-707. https://doi.org/doi:10.1177/0145445507301650

Ninci, J., Rispoli, M., Neely, L. C., \& Guz, S. (2018). Transferring picture exchange requests to receptive identification for children with ASD. Developmental Neurorehabilitation, 21(3), 178-187. https://doi.org/10.1080/17518423.2018.1437840

Queiroz, L. R., Guevara, V. S., Souza, C. A., \& Flores, E. P. (2020). Dialogic reading: Effects on independent verbal responses, verbal and non-verbal initiations, and engagement of children with autism spectrum disorder. International Journal of Psychology and Psychological Therapy, 20(1), 47-59. https://dialnet.unirioja.es/servlet/articulo?codigo $=7288617$

Quigley, J., Griffith, A. K., \& Kates-McElrath, K. (2018). A comparison of modeling, prompting, and a multicomponent intervention for teaching play skills to children with developmental disabilities. Behavior Analysis in Practice, 11(4), 315-326. https://doi.org/doi:10.1007/s40617-018-0225-0

Raulston, T. J., Hansen, S. G., Frantz, R., Machalicek, W., \& Bhana, N. (2019). A Parent-implemented playdate intervention for young children with autism and their peers. Journal of Early Intervention, Advance Online Publication. https://doi.org/10.1177/1053815119880943 
Roche, L., Sigafoos, J., Lancioni, G. E., O’Reilly, M. F., Van Der Meer, L., Achmadi, D., Green, V. A., Kagohara, D., Sutherland, D., Rayner, C. \& Marschik, P. B. (2014). Comparing tangible symbols, picture exchange, and a direct selection response for enabling two boys with developmental disabilities to access preferred stimuli. Journal of Developmental and Physical Disabilities, 26(3), 249-261. https://doi.org/doi:10.1007/s10882-013-9361-1

Saral, D., \& Ülke-Kürkçüoğlu, B. (2020). Least-to-most prompting in increasing frequency and diversity of pretend play in children with autism. Topics in Early Childhood Special Education. Advance Online Publication. https://doi.org/10.1177/0271121420942850

Schaefer-Whitby, P. J., Kucharczyk, S., \& Lorah, E. (2019). Teaching object exchange for communication to a young girl with autism spectrum disorder and visual impairment. Journal of Visual Impairment \& Blindness, 113(4), 372-380. https://doi.org/10.1177/0145482X19869521

Seaver, J. L., \& Bourret, J. C. (2014). An evaluation of response prompts for teaching behavior chains. Journal of Applied Behavior Analysis, 47(4), 777-792. https://doi.org/10.1002/jaba.159

Shepley, C., Lane, J. D., \& Ault, M. J. (2019). A review and critical examination of the system of least prompts. Remedial and Special Education, 40(5), 313-327. https://doi.org/10.1177/0741932517751213

Shillingsburg, M. A., \& Cariveau, T. (2016). Responding to conversational partners' behavior: Teaching children with autism strategies to recapture the interest of others. Evidence-Based Communication Assessment and Intervention, 10(3-4), 143-147. https://doi.org/10.1080/17489539.2016.1268671

Steinbrenner, J. R., Hume, K., Odom, S. L., Morin, K. L., Nowell, S. W., Tomaszewski, B., Szendrey, S., Mclntyre, N. S., Yücesoy-Özkan, Ş., \& Savage, M. N. (2020). Evidence-based practices for children, youth, and young adults with Autism. The University of North Carolina at Chapel Hill, Frank Porter Graham Child Development Institute, National Clearinghouse on Autism Evidence and Practice Review Team. https://ncaep.fpg.unc.edu/sites/ncaep.fpg.unc.edu/files/imce/documents/EBP\%20Report\%202020.pdf

Taylor, B. A., \& Hoch, H. (2008). Teaching children with autism to respond to and initiate bids for joint attention. Journal of Applied Behavior Analysis, 41(3), 377-391. https://doi.org/10.1901/jaba.2008.41-377

Tekin-İftar, E., \& Kırcaali-İftar, G. (2013). Özel eğitimde yanlı̧̧sız öğretim yöntemleri [Errorless teaching methods in special education] (3. baskı). Nobel Yayın Dağıtım.

Tetreault, A. S., \& Lerman, D. C. (2010). Teaching social skills to children with autism using point-of-view video modeling. Education and Treatment of Children, 33(3), 395-419. https://doi.org/10.1353/etc.0.0105

Thiemann-Bourque, K., Brady, N., McGuff, S., Stump, K., \& Naylor, A. (2016). Picture exchange communication system and pals: A peer-mediated augmentative and alternative communication intervention for minimally verbal preschoolers with autism. Journal of Speech, Language, and Hearing Research, 59(5), 1133-1145. https://doi.org/10.1044/2016 JSLHR-L-15-0313

Thiemann, K. S., \& Goldstein, H. (2004). Effects of peer training and written text cueing on social communication of school-age children with pervasive developmental disorder. Journal of Speech, Language, and Hearing Research, 47(1), 126-144. https://doi.org/10.1044/1092-4388(2004/012)

Topuz, C., \& Ulke-Kurkcuoglu, B. (2019). Increasing verbal interaction in children with autism spectrum disorders using audio script procedure. Journal of Autism and Developmental Disorders, 49(12), 4847-4861. https://doi.org/doi:10.1007/s10803-019-04203-w

Ülke-Kürkçüoğlu, B. (2015). A comparison of least-to-most prompting and video modeling for teaching pretend play skills to children with autism spectrum disorder. Educational Sciences: Theory \& Practice, 15(2), 499-517. https://doi.org/10.12738/estp.2015.2.2541

Van Der Meer, L., Kagohara, D., Roche, L., Sutherland, D., Balandin, S., Green, V. A., Marschik, P. B., \& Sigafoos, J. (2013). Teaching multi-step requesting and social communication to two children with autism spectrum disorders with three AAC options. Augmentative and Alternative Communication, 29(3), 222234. https://doi.org/10.3109/07434618.2013.815801

Vuran, S., \& Usluer, C. (2012). Sosyal öyküler. S. Vuran (Ed.), Sosyal yeterliklerin geliştirilmesi [Developing social competence] içinde (ss. 167-182). Vize Yayıncılık. 
Waddington, H., Sigafoos, J., Lancioni, G. E., O’Reilly, M. F., Van Der Meer, L., Carnett, A., Stevens, M., Roche, L., Hodis, F., Green, V. A., Sutherland, D., Lang, R., \& Marschik, P. B. (2014). Three children with autism spectrum disorder learn to perform a three-step communication sequence using an iPad®-based speech-generating device. International Journal of Developmental Neuroscience, 39(4), 59-67. https://doi.org/10.1016/j.ijdevneu.2014.05.001

Walsh, E., Holloway, J., \& Lydon, H. (2018). An evaluation of a social skills intervention for adults with autism spectrum disorder and intellectual disabilities preparing for employment in Ireland: A pilot study. Journal of Autism and Developmental Disorders, 48(5), 1727-1741. https://doi.org/10.1007/s10803-017-3441-5

West, E. A., \& Billingsley, F. (2005). Improving the system of least prompts: A comparison of procedural variations. Education and Training in Developmental Disabilities, 40(2), 131-144. https://www.jstor.org/stable/23880086

Wilson, E. R., Wine, B., \& Fitterer, K. (2017). An investigation of the matrix training approach to teach social play skills. Behavioral Interventions, 32(3), 278-284. https://doi.org/10.1002/bin.1473

Xin, J. F., \& Leonard, D. A. (2015). Using iPads to teach communication skills of students with autism. Journal of Autism and Developmental Disabilities, 45, 4154-4164. https://doi.org/doi:10.1007/s10803-014-2266$\underline{8}$

Yanardağ, M., Birkan, B., Yılmaz, I., Konukman, F., Agbuga, B., \& Lieberman, L. (2011). The effects of leasttomost prompting procedure in teaching basic tennis skills to children with autism. Kinesiology, 43(1), 44-55. https://digitalcommons.brockport.edu/pes_facpub/70/ 


\section{Ankara University Faculty of \\ Educational Sciences Journal of \\ Special Education}

2021, 22(4), 969-998
REVIEW

Recieved Date: 03.03.20

Accepted Date: 22.11 .20

OnlineFirst: 27.11 .20

\title{
Least-to-Most Prompting in Teaching Social Interaction and Communication Skills to Individuals with Autism Spectrum Disorder: A Systematic Review*
}

\author{
Burcu Ülke-Kürkçüoğlu (D)
}

\author{
Dinçer Saral (D)2
}

\begin{abstract}
Introduction: The purpose of this review was to examine the demographic, methodological and outcome measures of the studies using least-to-most prompting (LTM) to teach social interaction and communication skills to the individuals with ASD.

Method: Following a thorough literature search in four online databases (EBSCOhost, ScienceDirect, Jstor and SAGE) using multiple search terms, we identified 388 studies. From this identification, 35 empirical studies qualified for the inclusion criteria as follows: (a) including participants with autism, (b) using LTM, (c) employing a single-subject research design, (d) targeting at least one social communication or interaction skill, (e) publication between January 2003 and May 2020, (f) publication in a Turkish and/or English peer-reviewed journal.
\end{abstract}

Findings: Review of the treatment literature suggests that LTM is an effective method for the individuals with ASD who differ in age and gender to acquire the skills.

Discussion: Suggestions for further research are provided.

Keywords: Autism, social interaction, communication, errorless teaching, system of least prompts.

To cite: Ülke-Kürkçüoğlu, B., \& Saral, D. (2020). Least-to-most prompting in teaching social interaction and communication skills to individuals with autism spectrum disorder. Ankara University Faculty of Educational Sciences Journal of Special Education, 22(4), 969-998. https://doi.org/10.21565/ozelegitimdergisi.697976

\footnotetext{
*This article was presented as a poster presentation at $3^{\text {rd }}$ National Interdisciplinary Early Childhood Intervention Congress (UDEMKO 2016).

${ }^{1}$ Corresponded Author: Assoc. Prof., Anadolu University, E-mail: bulkekurkcuoglu@ anadolu.edu.tr, https://orcid.org/00000003-0187-9742

${ }^{2}$ Res. Assist., Hacettepe University, E-mail: dincersaral@ hacettepe.edu.tr, https://orcid.org/0000-0003-0795-255X
} 


\section{Introduction}

Deficits in social communication and interaction are core problems in individuals with autism spectrum disorders (ASD) (American Psychiatric Association, 2013). DSM-5 defines ASD as (a) restricted and repetitive patterns of interests and behaviors and (b) deficits in social interaction and communication. It is stated in the manual that the individuals with ASD have problems in restricted emotion sharing, making friends, eye contact, thus making them have difficulty in comprehending, sustaining and initiating social interaction and communication. Individuals with ASD are to acquire these skills in order to make meaningful communication with others, to be independent and solve any problems they face in daily life (Matson et al., 2007).

In literature, there are many methods and techniques to teach social communication and interaction skills. In this sense, it is strongly recommended to employ such evidence-based interventions as errorless teaching to teach various skills (Steinbrenner et al., 2020). One of the errorless teaching methods is least-to-most prompting (LTM)-also referred to as system of least prompts. In LTM, the adult starts the session by providing the least intrusive prompt and transitions to most intrusive prompts when necessary to obtain a correct response. However, the transitions between the prompts are made according to participant's response within response interval. LTM includes a prompt hierarchy of at least three levels (Barton \& Pavilanis, 2012; Seaver \& Bourret, 2014; Tekin-İftar \& Kircaali-İftar, 2013).

To our knowledge, there are only three review studies that include studies on LTM (Ault et al., 1989; Doyle et al., 1988; Shepley, Lane \& Ault, 2019). Doyle et al. (1988) evaluated studies that employed LTM in teaching procedure while Ault et al. (1989) analyzed studies that compared different interventions for individuals with moderate and severe disabilities and that included LTM. In this sense, only Shepley et al. (2019) focused on 123 peer-reviewed studies published between 1988-2016 on LTM which were identified through a database search on PsycInfo, ERIC and Medline by using relevant keywords. They examined the studies by participant characteristics, setting, LTM usage, effectiveness, efficacy and evidence-based criteria. However, there are no review studies that examine research on LTM for the individuals with ASD. It is seen that there has been an increasing, and yet few number of studies that employ LTM recently in Turkey (Bilmez, 2014; Kurnaz, 2018; Saral \& Ülke-Kürkçüoğlu, 2020; Topuz \& Ülke-Kürkçüoğlu, 2019; Ülke-Kürkçüoğlu, 2015; Yanardağ et al., 2011). Further, no studies examined research on teaching social communication and interaction skills to individuals with ASD. Thus, the current study aims at encouraging experts, researchers and implementers to employ LTM in training the individuals with ASD in Turkey.

The research questions were in the following: (a) What are the demographic characteristics of the participants (age and gender)?, (b) What is the distribution of implementers (researcher, teacher, etc.)?, (c) What are the intervention settings (home, school, etc.)?, (d) Which single-subject designs are used in the studies?, (e) What are the social interaction and communication skills taught?, (f) What is the distribution of LTM usage (alone, together with, etc.)?, (g) What is the prompting hierarchy used in the studies?, (h) What are the results of maintenance, generalization and social validity data?, (i) Which generalization sessions are held across?, (j) What are the results of interobserver data and procedural fidelity?, (k) What are the results of acquisition, maintenance, generalization and social validity?

\section{Method}

\section{Literature Search}

The current review examined the studies on teaching social interaction and communication skills through LTM between January 2003 and May 2020. Thus, a literature search was conducted on EBSCOhost, ScienceDirect, Jstor and SAGE using the keywords, "autism", "system of least", and "least to most (Tr. "ipucunun giderek arttırılması"). A total of 390 studies were identified during the initial search.

\section{Inclusion and Exclusion Criteria}

The following inclusion criteria for the studies were specified: (a) including participants with ASD, (b) employing LTM procedure, (c) employing a single-subject research design, (d) targeting social interaction and communication skill(s), (e) being published between January 2003-May 2020 and (f) being published in a peerreviewed Turkish or/and English journal. Furthermore, the studies were excluded if they did not (a) include participant(s) not diagnosed with ASD, (b) employ a single-subject research design, (c) were published before 2003. On the basis of the criteria, 35 articles of 390 were identified and included in the review. 


\section{Intercoder Agreement}

An independent coder who was a PhD candidate and a research assistant in Special Education department analyzed and coded \%50 of the included articles. The following formula was used for calculating intercoder agreement: [total agreement / (total agreement + total disagreement) $X$ 100]. The intercoder agreement was calculated as $100 \%$.

\section{Results}

\section{Participant Characteristics}

A total of 117 participants with ASD participated in the studies. 51 of the participants were between 2-5 years (e.g., Charlop \& Greenberg, 2009, Hansen et al., 2019), 31 between 6-9 (e.g., Thiemann \& Goldstein, 2004), 22 between 10-13 (e.g., Xin \& Leonard, 2015), 2 between 14-17 (e.g., Cannella-Malone et al., 2010; Lund \& Troha, 2008), and 7 between 18-21 (e.g., Walsh et al., 2018). 81 participants were male, and the rest were female.

\section{Implementer}

In 23 of the studies reviewed, the implementer was the researcher (e.g., Schaefer-Whitby et al., 2019) while a teacher implemented the procedure in four (e.g., Kern et al., 2007). A master student and an occupational therapist (Lund \& Troha, 2008), a teacher assistant (Xin \& Leonard, 2015), a peer (Thiemann-Bourque et al., 2016), both a peer and the researcher (Hansen et al., 2019) were also among the implementers. Parents were the implementers in three studies (Erturk et al., 2020; Hansen et al., 2018; Raulston et al., 2019), and mother and researcher in one study (Van Der Meer et al., 2013).

\section{Setting}

Of the studies reviewed, 12 (e.g., Tetreault \& Lerman, 2010) were conducted in a clinical setting, 14 (e.g., Lund \& Troha, 2008) in classroom and two in school (Queiroz et al., 2020; Xin \& Leonard, 2015). Five of the studies took place in home setting (Armendariz \& Hahs, 2019; Erturk et al., 2020; Raulston et al., 2019; Topuz \& Ülke-Kürkçüoğlu, 2019; Wilson et al., 2017) while two in both class and home (Cannella-Malone et al., 2010; Van Der Meer et al., 2013).

\section{Design}

Of the 35 studies reviewed, 14 employed multiple baseline design (e.g., Huskens et al., 2013, Waddington et al., 2014) and 12 used multiple probe design (e.g., Barton, 2015, Curiel et al., 2016). Two studies used AB design (Thiemann-Bourque et al., 2016; Schaefer-Whitby et al., 2019), one employed ABAB design (Kern et al., 2007) and changing criterion design. Four studies used alternating treatment design or adapted alternating design to compare LTM with another method (Ninci et al., 2018; Quigley et al., 2018; Topuz \& Ülke-Kürkçüoğlu, 2019; Van Der Meer et al., 2013), while one study employed ABCBCC (Barton et al., 2019).

\section{Dependent Variables}

21 studies measured only one dependent variable while the rest targeted more than two. The studies determining one dependent variable targeted manding (Alzyrayer et al., 2017; Alzyrayer et al., 2019; Lund \& Troha, 2008; Raulston et al., 2019; Roche et al., 2014; Schaefer-Whitby et al., 2019), asking questions (Huskens et al., 2013), play skills (Barton et al., 2019; Kourassanis et al., 2015; Quigley et al., 2018; Ülke-Kürkçüoğlu, 2015) receptive language (Curiel et al., 2016), joint attention (Hansen et al., 2018; Hansen et al., 2019), communicating through technology-aided instruction (Finke et al., 2017), social communication for job (Walsh et al., 2018) and initiating interaction (Charlop \& Greenberg, 2009) skills. Nine studies targeted greeting and waving hands (Thiemann \& Goldstein, 2004), manding and thanking (Waddington et al., 2014), play and communication skills (Barton, 2015; Barton et al., 2018), commenting and responding (D'Agostino et al., 2018), receptive language and manding (Ninci et al., 2018), initiating and elaborating interaction (Topuz \& Ülke-Kürkçüoğlu, 2019). The studies determining three to five dependent variables targeted eye contact, toy sharing and initiating interaction (Tetreault \& Lerman, 2010), manding, responding and commenting/greeting (Cannella-Malone et al., 2010; Xin \& Leonard, 2015), asking question, changing the topic and labeling (Shillingsburg \& Cariveau, 2016). 


\section{LTM Implementation}

LTM was implemented "throughout" the teaching procedure in 19 studies, while it was used in some parts or purposes of the study such as error correction in 16. In 13 studies of 19, LTM was used with other method(s) or technique(s) (e.g., Kern et al., 2007; Ülke-Kürkçüoğlu, 2015). In these studies, LTM was used with song (Kern et al., 2007), PECS (Cannella-Malone et al., 2010; Schaefer-Whitby et al., 2019; Thiemann-Bourque et al., 2016) contingent imitation (Barton, 2015), constant time delay and differential reinforcement (Alzrayer et al., 2017), activity schedule, reinforcement and modeling (Barton et al., 2018), social stories and milieu teaching (Raulston et al., 2019), progressive time delay, prompting and differential reinforcement (Alzrayer et al., 2020). On the other hand, LTM was used alone in the studies where it was implemented in some parts of the teaching procedure.

In the studies where LTM was used in some parts and purposes, it was used for error correction (Armendariz \& Hahs, 2019; Ninci et al., 2018; Thiemann \& Goldstein, 2004; Walsh et al., 2018; Wilson et al., 2017), script fading (Charlop \& Greenberg, 2009; Topuz \& Ülke-Kürkçüoğlu, 2019), adaptation (Curiel et al., 2016; Kourassanis et al., 2015; Shillingsburg \& Cariveau, 2016; Tetreault \& Leerman, 2010), teaching to use assistive technology devices (Van Der Meer et al., 2013; Waddington et al., 2014; Xin \& Leonard, 2015). Lastly, LTM was compared with video modeling (Ülke-Kürkçüoğlu, 2015) and modeling and modeling + LTM in one study (Quigley et al., 2018).

\section{Prompting Hierarchy}

Four studies used two-level prompting hierarchy of verbal-physical prompts or gesture-verbal prompts (Armendariz \& Hahs, 2019; Curiel et al., 2016; Ninci et al., 2018; Roche et al., 2014), while the rest used three-, four- and five-level prompting hierarchy (Cannella-Malone et al., 2010; Lund \& Troha, 2008; Xin \& Leonard, 2015). The first level was independent prompt in sixteen studies (e.g., Lund \& Troha, 2008; Huskens et al., 2013; Barton et al., 2018; Schaefer-Whitby et al., 2019). Further, a combination of gestural, verbal and physical prompts was used in a level in the hierarchy. (Alzrayer et al., 2017; Barton, 2015; Tetreault \& Lerman, 2010; ThiemannBourque et al., 2016; Ülke-Kürkçüoğlu, 2015; Waddington et al., 2014).

Of the studies reviewed, 16 used three-level prompting hierarchy (e.g., Alzrayer et al., 2019; Van Der Meer et al., 2013). 11 of these used only one prompt in any levels in the hierarchy (e.g., Huskens et al., 2013; Quigley et al., 2018; Topuz \& Kürkçüoğlu, 2019; Wilson et al., 2017). However, the rest used two or more prompts in one or more levels (e.g., Barton, 2015; Barton et al., 2018; D’Agostino et al., 2018; Tetreault \& Lerman, 2010).

\section{Maintenance}

Twenty-three of the studies measured maintenance (e.g., Armendariz \& Hahs, 2019; Walsh et al., 2018; Raulston et al., 2019) while 12 did not report information regarding to maintenance or follow-up (e.g., Hansen et al., 2019; Schaefer-Whitby et al., 2019).

\section{Generalization}

Twenty-one studies measured generalization. However, no data were provided in 14 studies. Fourteen studies only measured generalization across materials (e.g., Charlop \& Greenberg, 2009; Tetreault \& Lerman, 2010). One measured generalization across settings (Xin \& Leonard, 2015). Furthermore, only five studies measured generalization across people, settings and materials (Barton, 2015; Thiemann-Bourque et al., 2016; Topuz \& Ülke-Kürkçüoğlu, 2019; Ülke-Kürkçüoğlu, 2015; Walsh et al., 2018).

\section{Social Validity}

Fifteen of the studies collected social validity data. Only one collected the data from the participants (Van Der Meer et al., 2013). In four studies, social validity data were collected from parents, and from teachers in three studies. D'agostino et al. (2018) collected social validity data from both preschool and special education teachers, and Alzrayer et al. (2019) from teachers and teacher assistants. The data were also collected from teachers and master students (Thiemann \& Goldstein, 2004), both parents and teachers (Cannella -Mallone et al., 2010; Queiroz et al., 2020), and both parents and master students (Ülke-Kürkçüoğlu, 2015). Although authors in one study collected social validity data from parents, caregivers and classroom teachers of the participants and their in-class peers, they did not report any information regarding to the number of the consumers (Kern et al., 2007). Walsh et al. (2018) collected social validity data from participants, parents and teachers. Lastly, Shillingsburg and Cariveau (2016) did not report the shareholders. 


\section{Interobserver Agreement and Procedural Fidelity}

All studies, except two (Schaefer-Whitby et al., 2019; Xin \& Leonard, 2015), reported interobserver agreement data. On the other hand, all but four studies (Armendariz \& Hahs, 2019; Shillingsburg \& Cariveau, 2016; Schaefer-Whitby et al., 2019; Xin \& Leonard, 2015) reported procedural fidelity. Lastly, two studies did not report both interobserver agreement and procedural fidelity data (Schaefer-Whitby et al., 2019; Xin \& Leonard, 2015).

\section{Outcome Measures}

Acquisition

LTM was effective when used alone or with another method/technique in teaching target skills in 29 studies.

\section{Maintenance}

Seventeen of 23 studies which measured maintenance reported that the participants maintained the skills they had acquired (e.g., Alzrayer et al., 2019; Walsh et al., 2018). However, none of the participants could maintain exhibiting the skills in three studies (Armendariz \& Hahs, 2019; Barton et al., 2019; Shillingsburg \& Cariveau, 2016).

\section{Generalization} skills.

In three of 22 studies that measured generalization, a few participants could not generalize the target

\section{Social Validity}

In 12 of the studies that collected social validity data $(n=14)$, all consumers suggested positive opinions towards the procedure (e.g., Curiel et al., 2016; Hansen et al., 2019; Ülke-Kürkçüoğlu, 2015; Van Der Meer et al., 2013).

\section{Discussion}

In this review, we analyzed studies on teaching social interaction and communication skills using LTM and published between 2003 and 2020 in terms of participant characteristics, methodological parameters and outcome measures. It is notable that previous studies that include participants between 14-17 (Cannella-Malone et al., 2010; Lund \& Troha, 2008) and 18-21 (e.g., Walsh et al., 2018) years with ASD are fewer. Thus, future research is suggested to teach those skills to the individuals with ASD between 14-21 years.

As to the implementers, the researcher conducted the intervention in all studies except 11 (e.g., SchaeferWhitby et al., 2019). Furthermore, mostly teachers implemented the procedure in these 11 studies. However, no studies were conducted by a sibling. Therefore, future research may be conducted by siblings in addition to parents and peers.

Nearly a half of the studies $(n=16)$ was conducted in school (e.g., Barton, 2015; Charlop \& Greenberg, 2009; Hansen et al., 2019), five at home (e.g., Armendariz \& Hahs, 2019), two in both home and class (CannellaMalone et al., 2010; Van Der Meer et al., 2013). Similarly, Shepley et al. (2019) found that most of 123 studies were conducted in school settings. Fewer number of studies was conducted in community or home setting. Therefore, future research is warranted to further evaluate the effects of LTM in communal settings.

Most studies used multiple baseline design or multiple probe design. Also, a number of studies employed alternating or adapted alternating design or ABCBCC design to compare the effectiveness and efficacy of LTM with another method (Barton et al., 2019; Topuz \& Ülke-Kürkçüoğlu, 2019; Van Der Meer et al., 2013). Therefore, future studies can continue to further evaluate the effectiveness and efficacy of LTM by employing other research designs.

It is notable that most of the recent studies on teaching social interaction and communication skills include joint attention (Hansen et al., 2019), manding (Raulston et al., 2019), play skills (Barton et al., 2019) and initiating interaction (Armendariz \& Hahs, 2019). In general, of the studies reviewed, manding and play skills are targeted. However, only a handful of studies taught joint attention, toy sharing, initiating and maintaining conversation, 
asking and responding to questions and commenting skills. Thus, it is recommended future research be conducted for teaching those skills.

Limited number of studies aimed at investigating the effectiveness of LTM alone on teaching social interaction and communication skills (e.g., Roche et al., 2014). In addition, only one study compared LTM with another method, video modeling (Ülke-Kürkçüoğlu, 2015). Hence, future comparative studies for LTM and other methods can be suggested.

In general, gestural, verbal, model and physical prompts were included in the prompting hierarchy in the studies. However only two studies, conducted recently, included visual prompts (D'Agostino et al., 2018; Walsh et al.2018). Moreover, independent prompt was used in nearly one out of three of the studies. Researchers used independent prompt in the first level of the hierarchy to teach manding, asking and responding to questions, commenting and play skills (e.g., Lund \& Troha, 2008; Huskens et al., 2013). One possible reason for this could be that they aimed at teaching those skills in a natural way without an adult support at first despite the potential of higher numbers of errors. Thus, future research may probe this by comparing and investigating the number of errors in the studies in which independent prompt is the first level or vice versa.

The current review also analyzed the studies in terms of maintenance, generalization and social validity outcomes. Only 23 studies measured maintenance and/or follow-up. Future research is warranted to further measure maintenance in different periods.

Most of the studies $(n=21)$ measured generalization. Only a handful of studies measured three types of generalization across materials, adults and settings (Barton, 2015; Thiemann-Bourque et al., 2016; Topuz \& ÜlkeKürkçüoğlu, 2019; Ülke-Kürkçüoğlu, 2015; Walsh et al., 2018). Hence, future research should measure all types of generalization after the termination of intervention and conduct follow-up studies for generalization.

More than one-third of the studies $(n=15)$ collected social validity data through subjective evaluation mostly from teachers, parents and grad students (Alzrayer et al., 2019; Cannella-Mallone et al., 2010; D'agostino et al., 2018; Thiemann \& Goldstein, 2004). Further, only one study collected the data from the participants themselves (Van Der Meer et al., 2013). Future studies may collect social validity data from the participants towards the intervention or may use social comparison technique.

Of the studies reviewed, only ten of the total of 117 participants could not acquire the0020targeted skills (Armendariz \& Hahs, 2019; Lund \& Troha, 2008; Ninci et al., 2018; Tetreault \& Lerman, 2010). All participants who acquired the skills could maintain and generalized the targeted skills across different conditions. Future researchers should consider that LTM is an effective method to teach social interaction and communication skills to the individuals with ASD although the number of errors participants make can be higher.

There are a few limitations in the current review. First, an independent observer analyzed and coded only $30 \%$ of the studies reviewed due to time restriction. Second, Barton et al. (2019) taught play skills to a 3-year girl in two studies and reported them in one article. However, the data were analyzed separately (e.g., design, implementer). Third, the articles reviewed were identified through using relevant keywords in four different online databases. However, an internal hand search in the peer-reviewed journals was not conducted.

The current review study is limited to 33 single-subject studies identified using inclusion and exclusion criteria. Future meta-analysis studies can be conducted to calculate and compare the effect sizes of the intervention. In literature, LTM is commonly used and suggested as an effective method to teach various skills to the individuals with ASD at different ages and genders although the number of errors and incorrect responses may be higher compared to the other errorless teaching methods (e.g., Barton \& Wolery, 2008; Shepley et al., 2019). Thus, teachers or implementers who work with the individuals with ASD can employ LTM considering such parameters as student characteristics to teach various skills.

\section{Author's Contributions}

The study was designed as a systematic review by the first author and she wrote the manuscript of the study. The literature was scaned by the second author according to the title of the study and he analysed the studies included in this study descriptively. 
LEAST-TO-MOST PROMPTING IN TEACHING SOCIAL INTERACTION AND COMMUNICATION SKILLS TO INDIVIDUALS WITH AUTISM SPECTRUM DISORDER: A SYSTEMATIC REVIEW

\section{Acknowledgment}

procedure.

We thank to Research Assistant Çetin TOPUZ calculating the data of the study for intercoder agreement 